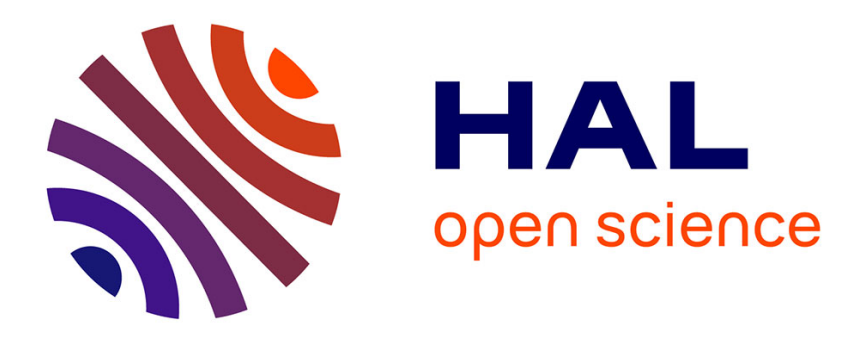

\title{
The physical properties of cadmium telluride
}

A.J. Strauss

\section{To cite this version:}

A.J. Strauss. The physical properties of cadmium telluride. Revue de Physique Appliquée, 1977, 12

(2), pp.167-184. 10.1051/rphysap:01977001202016700 . jpa-00244138

\section{HAL Id: jpa-00244138 \\ https://hal.science/jpa-00244138}

Submitted on 1 Jan 1977

HAL is a multi-disciplinary open access archive for the deposit and dissemination of scientific research documents, whether they are published or not. The documents may come from teaching and research institutions in France or abroad, or from public or private research centers.
L'archive ouverte pluridisciplinaire HAL, est destinée au dépôt et à la diffusion de documents scientifiques de niveau recherche, publiés ou non, émanant des établissements d'enseignement et de recherche français ou étrangers, des laboratoires publics ou privés. 


\title{
THE PHYSICAL PROPERTIES OF CADMIUM TELLURIDE (*)
}

\author{
A. J. STRAUSS \\ Lincoln Laboratory, Massachusetts Institute of Technology \\ Lexington, Massachusetts 02173, U. S. A.
}

\begin{abstract}
Résumé. - Cet article passe en revue les propriétés structurales, thermiques, mécaniques, optiques et électriques du tellurure de cadmium. Celles-ci sont par ailleurs comparées aux propriétés physiques des autres composés IIB-VIA.
\end{abstract}

\begin{abstract}
This paper reviews the structural, thermal, mechanical, optical, and electrical properties of CdTe and compares them with the physical properties of the other IIB-VIA compounds.
\end{abstract}

1. Introduction. - To introduce the papers that follow concerning specific properties and applications of CdTe, this paper gives a comprehensive survey of the whole range of physical properties of this material. A number of these properties will be compared with those of the other IIB-VIA compounds; although care has been taken to insure that the information presented for the other compounds is accurate, it should be noted that this information has been drawn primarily from published compilations of data, whereas for CdTe a systematic attempt was made to select the most reliable values from the current literature. Most of the figures included are reproductions of figures from published papers. These have been chosen mainly because of their suitability as illustrations for a review article, and their selection dœs not imply any judgment concerning the overall merit of the papers in which they appear relative to other papers on the same subjects.

2. Structural properties. - Figure 1 shows a portion of the periodic table that includes the elements of Groups IIB and VIA. Both Cd and Te are located in the fourth row of the table, with atomic numbers of 48 and 52, respectively, so that CdTe belongs to the same isoelectronic series as $\mathrm{Sn}$, InSb, and AgI. Since both $\mathrm{HgSe}$ and $\mathrm{HgTe}$ are semimetals, CdTe's average atomic number of 50 is the highest for any IIB-VIA semiconducting compound.

Table I lists the stable crystal structures at atmospheric pressure and the ionicities on the Phillips scale [1] of the 12 binary compounds formed by combining $\mathrm{Zn}$, $\mathrm{Cd}$, and $\mathrm{Hg}$ with $\mathrm{O}, \mathrm{S}, \mathrm{Se}$, and $\mathrm{Te}$. (For convenience, throughout the rest of the paper these will be referred to as the II-VI compounds, rather than the IIB-VIA

${ }^{*}$ ) This work was sponsored by the Department of the Air Force.

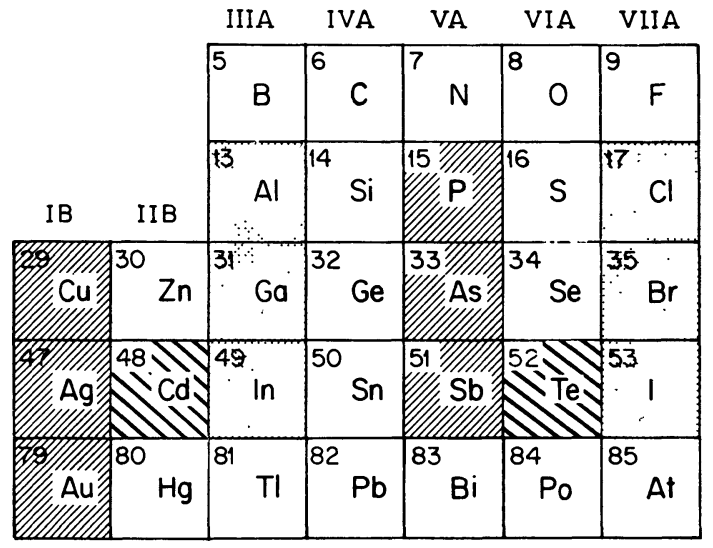

FIG. 1. - Portion of the periodic table including the elements of Groups IIB and VIA.

compounds. The compounds of the Group IIA elements are not considered here.) Like $\mathrm{ZnSe}, \mathrm{ZnTe}, \mathrm{HgSe}$ and $\mathrm{HgTe}$, as well as $\mathrm{HgS}$ above $377^{\circ} \mathrm{C}$ and $\mathrm{ZnS}$ up to about $1020^{\circ} \mathrm{C}$, bulk CdTe has the cubic zincblende structure, the binary analog of the diamond structure. In this structure each atom is tetrahedrally coordinated with four nearest neighbors of the other element. The hexagonal wurtzite structure of $\mathrm{ZnO}, \mathrm{CdS}, \mathrm{CdSe}$, and of $\mathrm{ZnS}$ above its transition temperature, also exhibits tetrahedral coordination, which is characteristic of compounds with sufficiently covalent binding. The Phillips ionicity of CdTe is $\mathbf{0 . 7 1 7}$, the highest for any of the II-VI compounds with either zincblende or wurtzite structure at room temperature. Thus all the compounds of this type have ionicities less than 0.785 , the value selected by Phillips as the threshold ionicity above which binary compounds are sufficiently ionic to have the octahedrally coordinated rocksalt structure. The only II-VI compound with rocksalt structure is $\mathrm{CdO}$, whose ionicity is just $\mathbf{0 . 7 8 5}$. 
TABLE I

Some physical properties of the IIB-VIA compounds

\begin{tabular}{|c|c|c|c|c|c|c|c|}
\hline Compound & $\begin{array}{c}\text { Crystal } \\
\text { structure }\left({ }^{a}\right)\end{array}$ & $\begin{array}{c}\text { Phillips } \\
\text { ionicity }\left({ }^{b}\right)\end{array}$ & $\begin{array}{c}\text { Lattice } \\
\text { constant } \\
(\AA)\left({ }^{c}\right)\end{array}$ & $\begin{array}{c}\text { Lattice } \\
\text { mismatch } \\
\text { with CdTe } \\
(\%)\end{array}$ & $\begin{array}{c}\text { Energy gap } \\
\text { at } \sim 2 \mathrm{~K} \\
(\mathrm{eV})\left({ }^{c}\right)\end{array}$ & $\begin{array}{l}\text { Spin-orbit } \\
\text { splitting } \\
(\mathrm{eV})\left({ }^{c}\right)\end{array}$ & $\begin{array}{l}\text { Conduc- } \\
\text { tivity type }\end{array}$ \\
\hline $\mathrm{ZnO}$ & W & 0.616 & $\begin{array}{l}a=3.250 \\
c=5.207\end{array}$ & -29.1 & 3.435 & -0.005 & $\mathrm{n}$ \\
\hline $\mathrm{ZnS}$ & $\mathrm{Z} \rightarrow \mathrm{W}$ & 0.623 & 5.409 & -16.5 & $\begin{array}{l}3.839(\mathrm{Z}) \\
3.912(\mathrm{~W})\end{array}$ & $0.072(\mathrm{Z})$ & $\mathrm{n}$ \\
\hline $\mathrm{ZnSe}$ & Z & 0.630 & 5.669 & -12.5 & 2.818 & 0.43 & $\mathrm{n},(\mathrm{p})$ \\
\hline $\mathrm{ZnTe}$ & Z & 0.609 & 6.103 & -5.8 & 2.391 & 0.93 & $\mathrm{p}$ \\
\hline $\mathrm{CdO}$ & $\mathbf{R}$ & 0.785 & 4.695 & & & & $\mathrm{n}$ \\
\hline CdS & W & 0.685 & $\begin{array}{l}a=4.137 \\
c=6.716\end{array}$ & -9.7 & 2.583 & 0.066 & $\mathrm{n}$ \\
\hline $\mathrm{CdSe}$ & W & 0.699 & $\begin{array}{l}a=4.298 \\
c=7.016\end{array}$ & -6.2 & 1.841 & 0.42 & $\mathrm{n}$ \\
\hline $\begin{array}{l}\mathrm{CdTe} \\
\mathrm{HgO}\end{array}$ & $\begin{array}{c}\mathrm{Z} \\
\mathrm{O}, \mathrm{C}\end{array}$ & 0.717 & $\begin{array}{c}6.481 \\
a=6.612 \\
b=5.520 \\
c=3.521\end{array}$ & - & 1.606 & 0.91 & $\mathrm{n}, \mathrm{p}$ \\
\hline HgS & $C \rightarrow Z$ & 0.79 & $\begin{array}{l}a=4.146 \\
c=9.497\end{array}$ & & 2.090 & & \\
\hline $\mathrm{HgSe}$ & $\mathrm{Z}$ & 0.68 & 6.085 & -6.1 & Semimetal & $\sim 0.45$ & $\mathrm{n}$ \\
\hline HgTe & $\mathrm{Z}$ & 0.65 & 6.460 & -0.3 & Semimetal & $\sim 1.1$ & $\mathrm{n}, \mathrm{p}$ \\
\hline
\end{tabular}
1967.

(a) $\mathrm{Z}=$ zincblende, $\mathrm{W}=$ wurtzite, $\mathrm{R}=$ rocksalt, $\mathrm{C}=$ cinnabar, $\mathrm{O}=$ orthorhombic.

(b) Ref. [1] (c) See Physics and Chemistry of II-VI Compounds, AvEn, M. and PrEnER, J. S., Eds. (North-Holland, Amsterdam)

Figure 2 reproduces a photograph, published by Hilsum and Rose-Innes [2], of a model of the zincblende structure in which the atoms of one element are represented by black spheres and those of the other element by white spheres. The vertical direction in the photograph is parallel to a $<111>$ axis. The model illustrates the tetrahedral configuration of nearest neighbors around each atom. It also shows that there are two types of $\{111\}$ planes that alternate with each other, one consisting entirely of atoms of one element and the other consisting entirely of atoms of the other element, while the $\{110\}$ planes contain equal numbers of the two kinds of atoms. As shown by

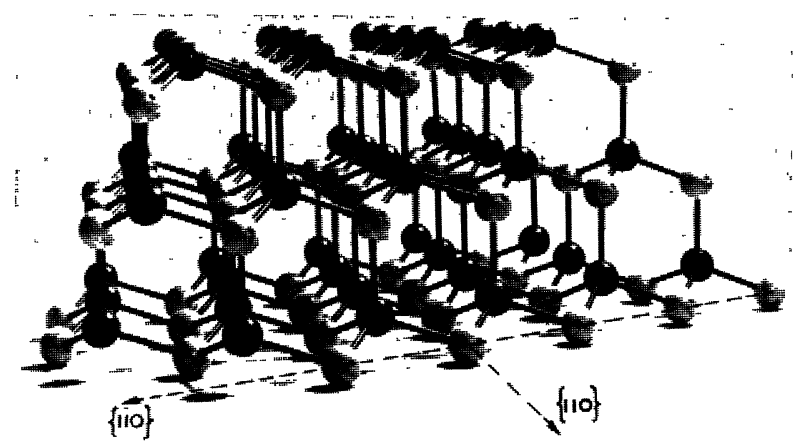

FIG. 2. - A model of the zincblende structure (Hilsum and Rose-Innes, Ref. [2]). the model, in which the uppermost layer consists of black spheres and the lowest layer of white spheres, the surfaces of a (111)-oriented sample are formed by planes of the two opposite types, so that one surface of a CdTe sample with this orientation consists of $\mathrm{Cd}$ atoms and the other of $\mathrm{Te}$ atoms. By convention, surfaces consisting of Group II atoms are designated as $A$ surfaces and those consisting of Group VI atoms as $B$ surfaces. The two types of surfaces have quite different chemical properties, as illustrated by figure 3 , which
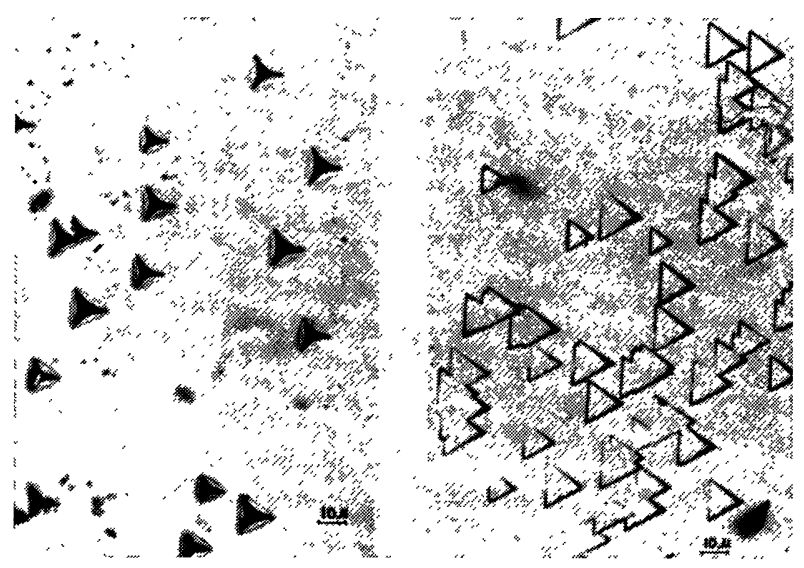

FIG. 3. - Etch pits on the $\{111\}$ surface of CdTe. Left : A surface ; right : B surface (Inoue et al., Ref. [3]). 
shows the etch pits that Inoue, Teramoto, and Takayanagi [3] obtained by etching CdTe $\{111\}$ surfaces with a solution containing nitric acid, silver nitrate, and potassium dichromate. The pits on both surfaces are triangular, with sides in $\langle 110\rangle$ directions, but those on the $A$ surface (shown on the left) are pyramidal or conical, while those on the $B$ surface (shown on the right) are flat-bottomed.

Although the stable form of CdTe is the zincblende phase, which is always obtained for bulk samples at atmospheric pressure, thin films containing various proportions of the wurtzite phase can be prepared by vacuum deposition. Shalimova et al. [4] and Spinulescu-Carnaru [5] have reported that films with pure wurtzite structure are obtained by deposition on heated substrates when CdTe and metallic $\mathrm{Cd}$ are cœvaporated in an Ar atmosphere of $10^{-2}$ torr.

When bulk CdTe is subjected to high pressure, the zincblende form is transformed to the rocksalt structure at a transition pressure of $35 \mathrm{kbar}[6,7]$. The variation in electrical resistance with pressure, as reported by $\mathrm{Yu}$ and Gielisse [7], is shown in figure 4.

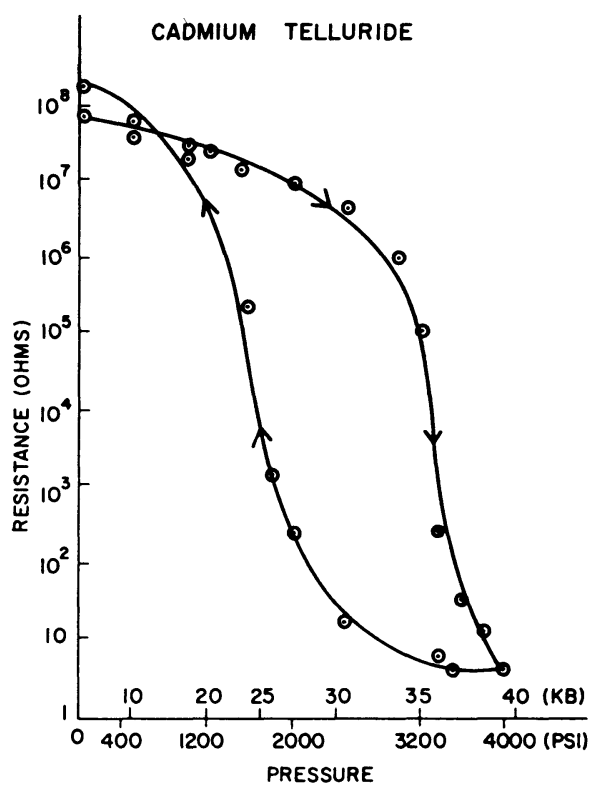

FIG. 4. - Electrical resistance of CdTe vs increasing and decreasing pressure ( $\mathrm{Yu}$ and Gielisse, Ref. [7]).

With increasing pressure (upper curve) the resistance at first decreases gradually, then drops abruptly by about 6 orders of magnitude at the transition point. There is marked hysteresis when the pressure is reduced (lower curve), but the rocksalt phase is not retained at atmospheric pressure. The decrease in volume accompanying the zincblende-to-rocksalt transformation is reported by Mariano and Warekois [8] and by Cline and Stephens [6] to be between 15 and $20 \%$. Both CdS and CdSe also transform to conducting rocksalt phases at high pressures, while $\mathrm{HgSe}$, and $\mathrm{HgTe}$ are transformed to the cinnabar structure.
Samara and Drickamer [9] report transitions of $\mathrm{ZnS}$, $\mathrm{ZnSe}$, and $\mathrm{ZnTe}$ to conducting phases of unknown structure at pressures exceeding $100 \mathrm{kbar}$.

The lattice constants of the II-VI phases stable at room temperature and atmospheric pressure are listed in table I, together with the percentage differences in lattice constant between $\mathrm{CdTe}$ and the compounds with zincblende and wurtzite structures. The most probable value for the lattice constant of CdTe is $6.481 \AA$. Although Medvedev et al. [10] have reported a systematic dependence of lattice constant on carrier concentration for single-crystal samples, with values as high as $6.484 \AA$ measured for high-resistivity specimens, no such variation was observed in similar experiments by Vaipolin and Rud' [11], who obtained values of $6.4818 \pm 0.003 \AA$. Cadmium telluride has the largest lattice constant of any II-VI compound. Because the difference between the constants for $\mathrm{CdTe}$ and $\mathrm{HgTe}$ is only $0.3 \%$, high-quality epitaxial layers of $\mathrm{Hg}_{1-x} \mathrm{Cd}_{x} \mathrm{Te}$ solid solutions covering the entire alloy composition range can be grown on CdTe substrates [12].

The structural properties of $\mathrm{CdTe}$ at $300 \mathrm{~K}$ are summarized in table II. Crystals can be cleaved quite

TABLE II

Structural properties of $\mathrm{CdTe}$ at $300 \mathrm{~K}$

Crystal structure

Space group

Zincblende

Cleavage plane

Molecules per unit cell

Molecular weight (g)

Lattice constant $(\AA)$

F $\overline{4} 3 \mathrm{~m}$

$\{110\}$

4

240.00

6.481

Shortest Cd-Te distance ( $\AA$ )

2.806

Molar volume $\left(\mathrm{cm}^{3}\right)$

40.99

Conc. of Cd sites $\left(\mathrm{cm}^{-3}\right)$

$\mathrm{X}$-ray density $\left(\mathrm{g} \mathrm{cm}^{-3}\right)$

$1.469 \times 10^{22}$

5.855

readily on the $\{110\}$ planes. The value listed for the shortest Cd-Te distance, $2.806 \AA$, was calculated on the assumption that $\mathrm{CdTe}$ has the ideal zincblende structure. From a structure-factor analysis of the measured intensities of x-ray diffraction lines, Vaipolin [13] has concluded that the $\mathrm{Cd}$ atoms are displaced along the $\langle 111\rangle$ directions from their ideal positions, so that each $\mathrm{Cd}$ atom is at a distance of $2.775 \AA$ from three of the neighboring Te atoms and $2.908 \AA$ from the fourth.

3. Thermal and mechanical properties. - The linear thermal expansion coefficient of CdTe, $\alpha \equiv(1 / l)$ $(\mathrm{d} l / \mathrm{d} T)$, is $(4.9 \pm 0.1) 10^{-6} \mathrm{~K}^{-1}$ at room temperature and increases with increasing temperature $[14,15]$. Williams, Tomlinson, and Hampshire [14] report that at $420^{\circ} \mathrm{C} \alpha=5.67 \times 10^{-6} \mathrm{~K}^{-1}$ and the lattice constant is $6.4955 \AA$, compared with $6.4809 \AA$ at room temperature. Below room temperature $\alpha$ 
decreases, becoming negative at $62 \pm 2 \mathrm{~K}$, as shown in figure 5. The circles represent the data of Greenough and Palmer [16] for a single crystal measured along a $<100>$ axis, the crosses and triangles those of other

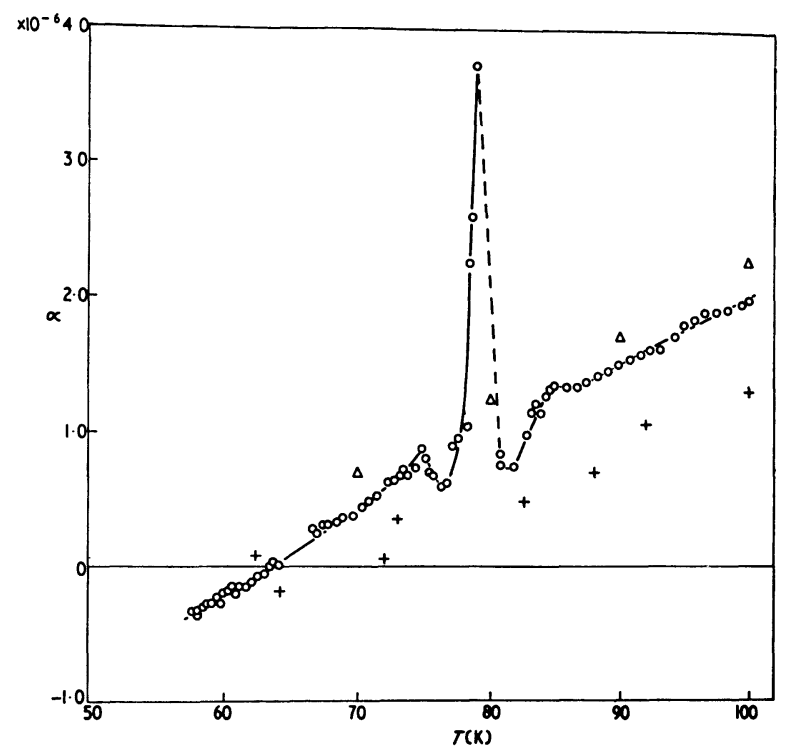

Fig. 5. - Linear thermal expansion coefficient of CdTe vs temperature (Greenough and Palmer, Ref. [16]).

authors for polycrystalline samples. The strong anomaly found by Greenough and Palmer, which peaks at $79 \mathrm{~K}$, was not confirmed in subsequent singlecrystal measurements by Smith and White [15]. The fact that the anomaly occurs very close to liquid nitrogen temperature seems somewhat suspicious.

As the temperature is decreased below $60 \mathrm{~K}$, $\alpha$ initially becomes more and more negative. As shown in figure 6, where the data of Smith and White

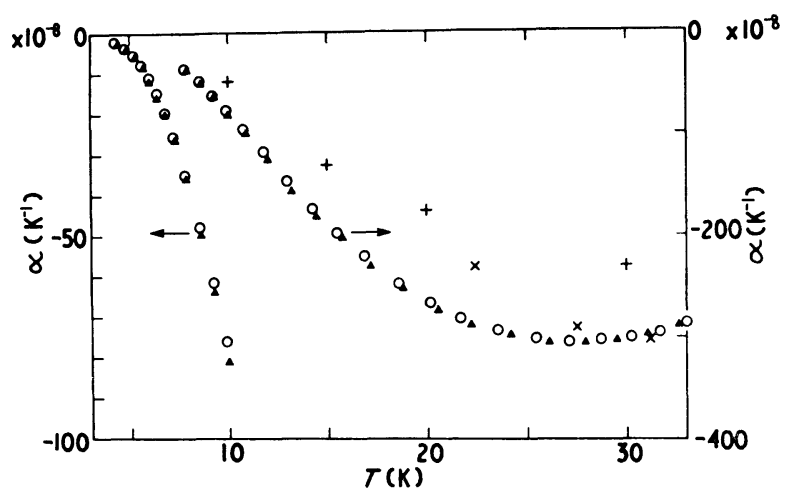

Fig. 6. - Linear thermal expansion coefficient of CdTe vs temperature (Smith and White, Ref. [15]).

[15] are represented by the circles and triangles and those of other authors by the crosses and $x$ 's, $\alpha$ reaches a maximum negative value of about $-3.0 \times 10^{-6}$ $K^{-1}$ at $27 \mathrm{~K}$. It then decreases in magnitude but remains negative down to absolute zero. Negative expansion coefficients are also exhibited by other zincblende-structure compounds at low temperatures, but CdTe represents an extreme case, as shown by the results of Smith and White [15] for Ge, GaAs, $\mathrm{ZnS}$, $\mathrm{ZnSe}$, and CdTe given in figure 7 . In this figure the

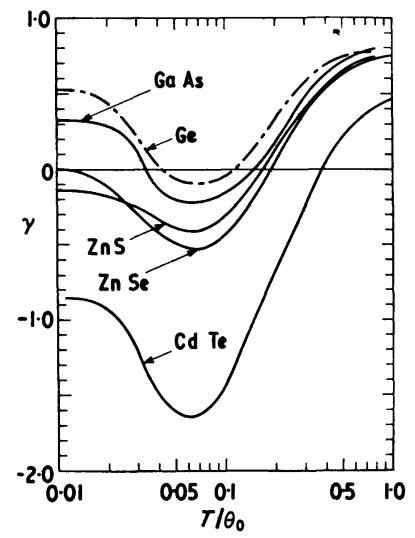

FIG. 7. - Grüneisen parameter vs reduced temperature for crystals with diamond or zincblende structure (Smith and White, Ref. [15]).

Grüneisen parameter $\gamma$ is plotted against the reduced temperature relative to the Debye temperature. This parameter is proportional to $\alpha$ times the product of the molar volume and bulk modulus divided by the specific heat, and it therefore has the same sign as $\alpha$.

Figure 8 shows the thermal conductivity $\kappa$ measured by Slack [17] between 3 and $300 \mathrm{~K}$ for single-crystal

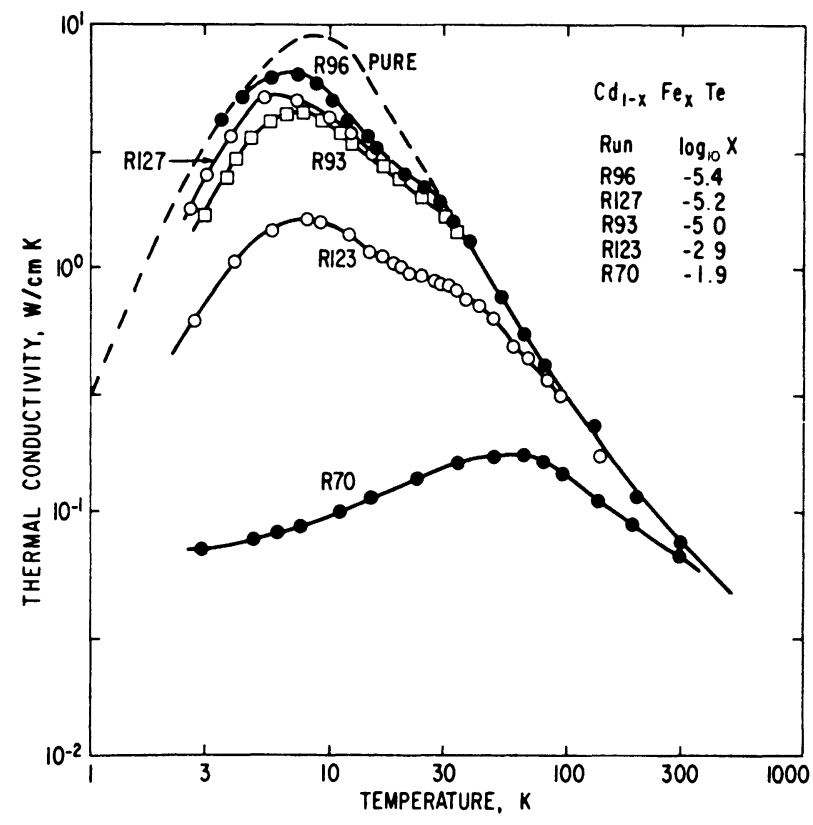

FIG. 8. - Thermal conductivity of Fe-doped CdTe vs temperature (Slack, Ref. [17]).

samples of CdTe containing various amounts of $\mathrm{Fe}$. For these samples the electronic contribution to $\kappa$ is insignificant compared to the lattice phonon contribution. The strong, structured decrease in $\kappa$ with increas- 
ing Fe concentration is attributed by Slack to resonant phonon scattering resulting from the absorption of phonons to produce electronic transitions among the 5 low-lying d-shell levels of the isolated $\mathrm{Fe}^{2+}$ ions. Since even his purest sample contained enough Fe to cause appreciable scattering, Slack estimated the curve labelled pure on the basis of the $\kappa$-vs-T curves for the other II-VI compounds, all of which exhibit a characteristic maximum at low temperature. Sood, Singh, and Verma [17A] obtained a theoretical curve that is in reasonable agreement with the pure curve (although their curve was fitted to Holland's earlier experimental data [17B], since it was published prior to Slack's paper) by summing the separate contributions to the conductivity that they calculated for the transverse and longitudinal acoustic phonons.

The thermal conductivity at $300 \mathrm{~K}$ for CdTe, $0.075 \mathrm{~W} \mathrm{~cm}^{-1} \mathrm{~K}^{-1}$, is the lowest for any of the tetrahedrally coordinated II-VI compounds except HgSe and $\mathrm{HgTe}$. The values for these and several other materials are shown in figure 9 , which is a plot given by

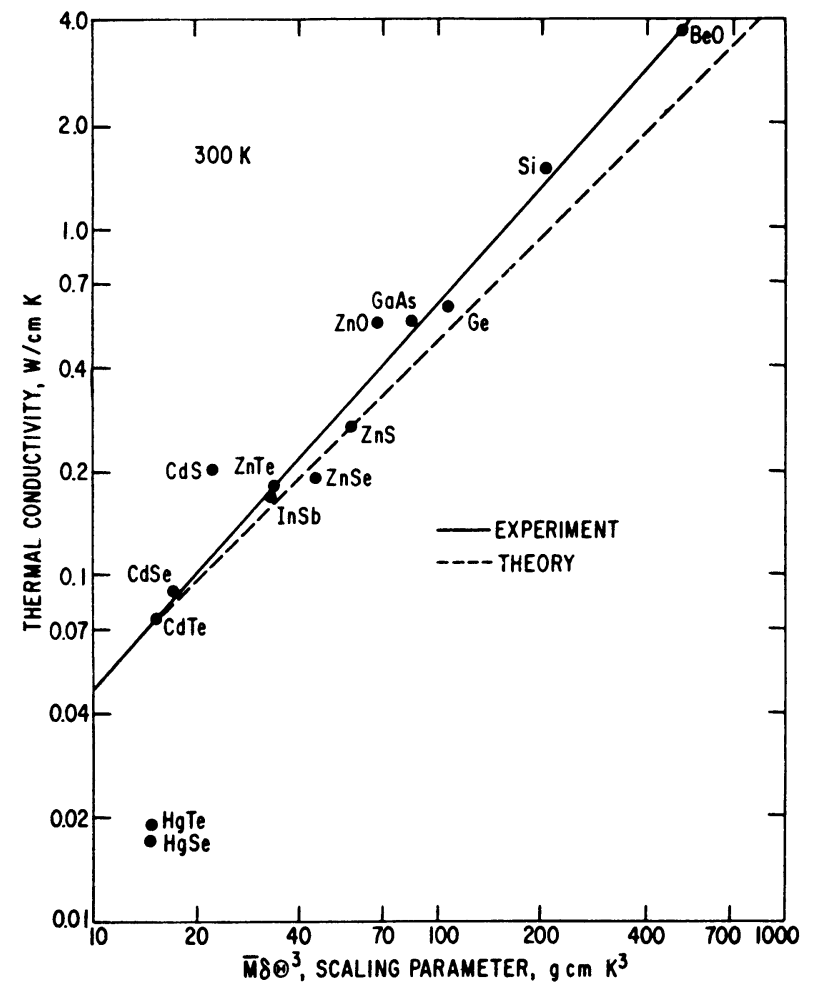

FIG. 9. - Thermal conductivity vs scaling parameter for crystals with tetrahedrally coordinated structures (Slack, Ref. [17]).

Slack [17] of $\kappa$ at $300 \mathrm{~K}$ as a function of the scaling parameter $\overline{\mathrm{M}} \delta \theta^{3}$, where $\bar{M}$ is the average atomic mass, $\delta$ is the cube root of the average volume per atom, and $\theta$ is the Debye temperature at absolute zero. All the points fall close to a straight line except those for $\mathrm{HgSe}$ and $\mathrm{HgTe}$, which have conductivities only about $25 \%$ as high as expected.

The thermal and mechanical properties of CdTe at $300 \mathrm{~K}$ are summarized in table III. The heat capacity
TABLE III

Thermal and mechanical properties of CdTe at $300 \mathrm{~K}$
Linear expansion coeff. $\left(\mathrm{K}^{-1}\right)\left({ }^{a}\right)$

Thermal conductivity $\left(\mathrm{W} \mathrm{cm}^{-1} \mathrm{~K}^{-1}\right)\left(^{b}\right)$

Heat capacity, $C_{\mathrm{p}}\left(\mathrm{cal} \mathrm{g-atom} \mathrm{K}^{-1} \mathrm{~K}^{-1}\right)\left({ }^{c}\right)$

Isothermal compressibility $\left(\mathrm{kbar}^{-1}\right)\left(^{(d)}\right.$

Elastic constants $\left({ }^{e}\right)$

$C_{11}\left(\mathrm{~N} \mathrm{~m}^{-2}\right)$

$C_{12}\left(\mathrm{~N} \mathrm{~m}^{-2}\right)$

$C_{44}\left(\mathrm{~N} \mathrm{~m}^{-2}\right)$

Microhardness $\left(\mathrm{kp} \mathrm{mm}^{-2}\right)(f)$

(a) Refs. [14, 15].

(b) Ref. [17].

(c) Ref. [18]

(d) Ref. [6].

(e) Refs. $[16,19,20]$.

(f) Ref. [22].
$(4.9 \pm 0.1) \times 10^{-6}$ 0.075

5.9

$3.96 \times 10^{-3}$

$(5.35 \pm 0.03) \times 10^{10}$

$(3.70 \pm 0.05) \times 10^{10}$

$(2.02 \pm 0.03) \times 10^{10}$

55 to 140 value, $5.9 \mathrm{cal} \mathrm{g}$-atom $^{-1} \mathrm{~K}^{-1}$, was read off the curve of $\mathrm{C}_{p}$ vs T published by Rusakov, Vekilov, and Kadyshevich [18]. The range of values given for each of the elastic constants includes the results given by McSkimin and Thomas [19], Vekilov and Rusakov [20] and Greenough and Palmer [16].

The variation of these constants with temperature was determined both by Vekilov and Rusakov and by Greenough and Palmer. Their results for $77 \mathrm{~K}$ are in good agreement with each other but not with the earlier data of Berlincourt, Jaffe, and Shiozawa [21] at this temperature. The range of microhardness values listed in table III was observed by Swaminathan, Selim, and Kröger [22] in measurements made in the dark on In-doped samples that had been annealed at various temperatures and $\mathrm{Cd}$ pressures. They found that the dark values increased with increasing carrier concentration, while the microhardness could be either increased or decreased by illumination, depending upon the annealing conditions. Changes in the mechanical properties of $\mathrm{CdTe}$ with carrier concentration and illumination have also been observed by Carlsson and Ahlquist [23] who found that the yield stress in compression increased with increasing carrier concentration for both $\mathrm{n}$ - and p-type samples and that the yield stress and crack propagation were both increased by illumination. They attributed the latter effects to a light-induced decrease in mobile dislocation density.

Values of the Debye temperature $\theta_{\mathbf{D}}$ for CdTe have been obtained from several types of experimental data. Analyses of x-ray diffraction intensity data for 96 to $300 \mathrm{~K}$ by Walford and Schœffel [24] and for 281 to $608 \mathrm{~K}$ by Zubik and Valvoda [25] show that over these intervals the $\mathrm{x}$-ray Debye temperature is close to $140 \mathrm{~K}$, essentially independent of temperature. Birch [26] has determined the temperature dependence of $\theta_{\mathrm{D}}$ between 1.8 and $25 \mathrm{~K}$ from heat capacity data over this range. He obtained a limiting value of $160 \pm 2 \mathrm{~K}$ for $\theta_{\mathrm{D}}$ at absolute zero, in very good agreement with the values of $161 \pm 4$ and $162.7 \mathrm{~K}$ found 
by Vekilov and Rusakov [20] and by Greenough and Palmer [16], respectively, by extrapolating elastic constant data to absolute zero. The Debye temperatures of the tetrahedrally coordinated II-VI compounds are compared in figure 10, which is a plot given by

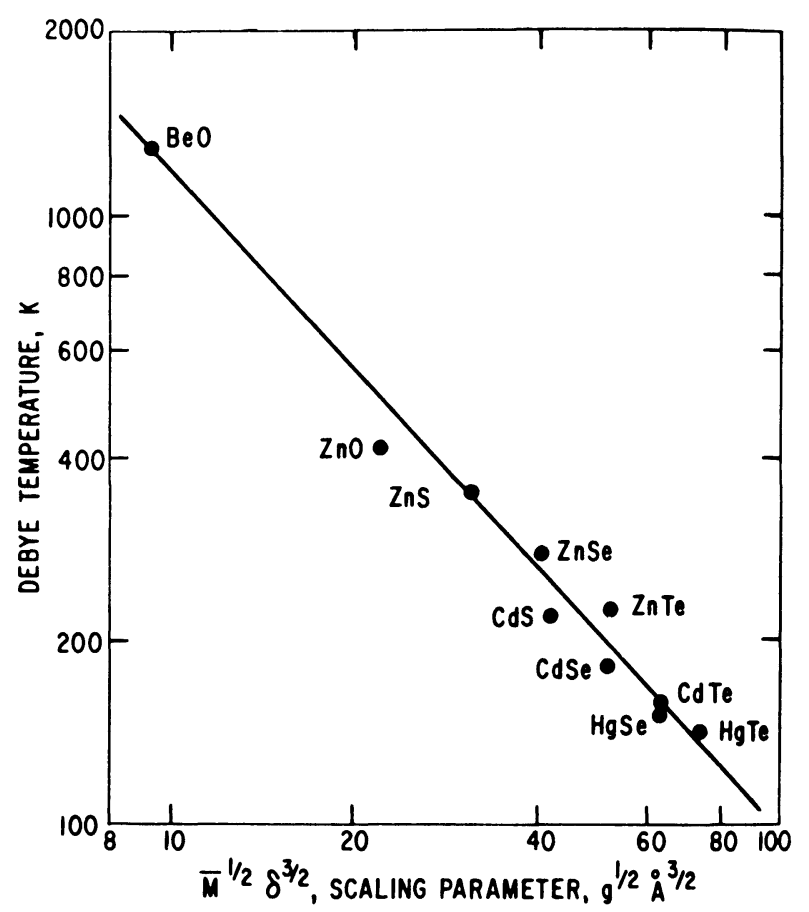

FIG. 10. - Debye temperature vs scaling parameter for tetrahedrally coordinated II-VI compounds (Slack, Ref. [17]).

Slack [17] of $\theta_{\mathbf{D}}$ at absolute zero as a function of the scaling parameter $\left(\bar{M} \delta^{3}\right)^{1 / 2}$, where $\bar{M}$ and $\delta$ have the same significance as above. The only compounds with Debye temperatures lower than that of CdTe are $\mathrm{HgSe}$ and HgTe.

All the thermal and mechanical properties of a material depend ultimately on its normal modes of vibration, as represented by the phonon dispersion relation. A determination of this relation for $\mathrm{CdTe}$ at $300 \mathrm{~K}$ has been made by Rowe et al. [27] by means of neutron inelastic scattering measurements. Their results are shown in figure 11, which gives the phonon frequencies as a function of the reduced wave vector, $\zeta=a q / 2 \pi$, for the [100], [111], and [110] directions of

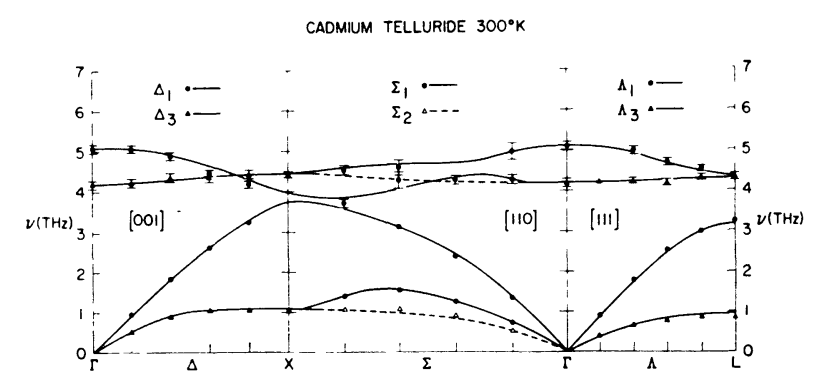

FIG. 11. - Phonon dispersion relation for CdTe (Rowe et al., Ref. [27]). propagation. The letters $\Gamma, \mathrm{X}$ and $\mathrm{L}$ refer to the symmetry points at the center of the Brillouin zone, the (100) zone boundary, and the (111) zone boundary, respectively. The symbols in the figure represent the experimental values for the longitudinal optical, transverse optical, longitudinal acoustic, and transverse acoustic phonons, while the solid lines represent the calculated results obtained by fitting a 14-parameter shell model to the experimental data for the elastic constants, static and high-frequency dielectric constants, and piezoelectric constant of $\mathrm{CdTe}$, as well as the phonon frequencies. Plumelle and Vandevyver [28] have recently used an 11-parameter rigid-ion model to fit the elastic constant and phonon frequency data. Table IV lists the phonon frequencies

\section{TABLE IV}

Symmetry-point phonon frequencies $(\mathrm{THz})$ in $\mathrm{CdTe}$ at $300 \mathrm{~K}\left({ }^{a}\right)$

$\begin{array}{cccc}\begin{array}{c}\text { Phonon } \\ \text { branch }\end{array} & \Gamma & \mathrm{X} & \mathrm{L} \\ - & - & - & - \\ \text { LO } & 5.08 & - & 4.33 \\ \text { TO } & 4.20 & 4.44 & 4.33 \\ \text { LA } & 0 & - & 3.25 \\ \text { TA } & 0 & 1.05 & 0.88\end{array}$

(a) Ref. [27].

measured by Rowe et al. [27] at $\Gamma, \mathrm{X}$ and L. They note that the values for the longitudinal and transverse optic modes of 5.08 and $4.20 \mathrm{THz}$, respectively, are in good agreement with the values of 5.03 and $4.22 \mathrm{THz}$ obtained by Perkowitz and Thorland [29] from farinfrared reflectivity data for n-type CdTe.

4. Optical properties. - We will now turn our attention to the interaction of $\mathrm{CdTe}$ with electromagnetic radiation, first considering $\gamma$-rays and then optical photons. Figure 12, which reproduces a plot given by Serreze et al. [30] shows the $\gamma$-ray absorption coefficients calculated for $\mathrm{CdTe}, \mathrm{Ge}$, and $\mathrm{Si}$ over the photon energy range from 20 to $2000 \mathrm{keV}$. For Si up to about $30 \mathrm{keV}$ and for $\mathrm{CdTe}$ and $\mathrm{Ge}$ up to about $100 \mathrm{keV}$, the total absorption is essentially equal to the absorption due to the photoelectric effect (curves labelled PE), which is highest for CdTe because it has the highest atomic number of the three materials - an average of 50, compared with 32 for Ge and 14 for Si. With increasing energy, as the cross section for the photoelectric effect decreases, absorption due to Compton scattering becomes increasingly important and eventually dominant. Gamma rays that initially undergo Compton scattering may then generate carriers by the photoelectric effect. Siffert et al. [31] have reported that in one series of experiments this multiple process contributed about half the counts forming the full-energy photoelectric peak. 


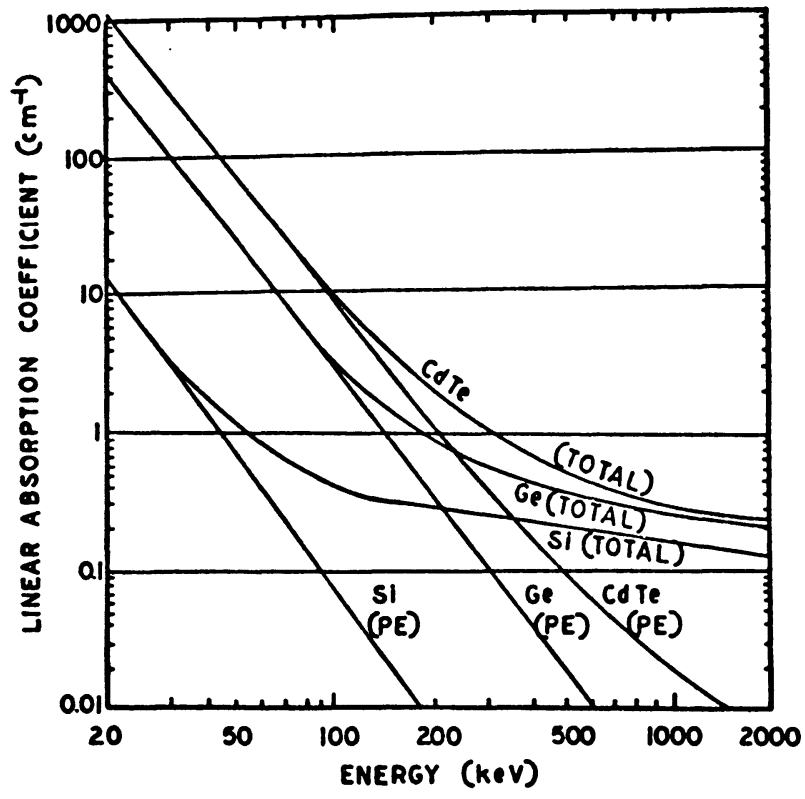

FIG. 12. - Gamma-ray absorption coefficients vs photon energy for CdTe, Ge, and Si (Serreze et al., Ref. [30]).

Figure 13 shows the temperature dependence reported by Alberigi Quaranta et al. [32] for the energy loss associated with the production of one electron-hole pair in CdTe by ionizing radiation. The data were

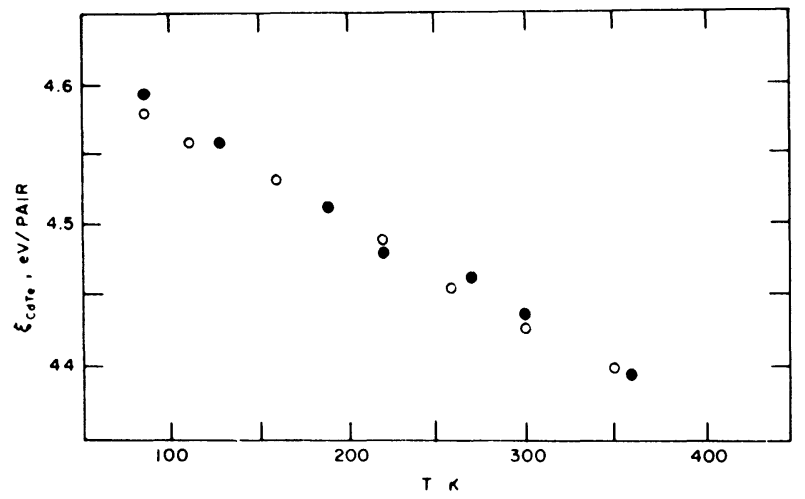

FIG. 13. - Energy loss associated with production of electronhole pairs in CdTe as a function of temperature (Alberigi Quaranta et al., Ref. [32]).

obtained by measurements on semi-insulating samples in which $5.477 \mathrm{MeV}$ alpha particles from ${ }^{241} \mathrm{Am}$ were used to generate the carrier pairs. It is assumed that the same energy per pair is required for generation by $\gamma$-rays. The value measured at $300 \mathrm{~K}$ was $4.43 \mathrm{eV}$, in very good agreement with the value of $4.46 \mathrm{eV}$ obtained by Cornet et al. [33] in measurements on surfacebarrier detectors fabricated from low-resistivity (10$200 \Omega . \mathrm{cm}$ ) n-type CdTe. The agreement at $77 \mathrm{~K}$ is not as good, with values of 4.58 and $4.75 \mathrm{eV}$ obtained by Alberigi Quaranta et al. [32] and Cornet et al. [33], respectively.
The interactions of optical photons with a semiconductor, unlike those of high-energy ionizing radiation, are determined by the details of the semiconductor's electronic and mechanical properties. We may distinguish three regimes of photon energy with different characteristic optical absorption mechanisms. For photon energies greater than the semiconductor energy gap $E_{\mathrm{g}}$ there are very strong absorptions due to excitation of electrons from the valence bands or atomic core levels to the conduction bands and, for sufficiently high energies, due to photoemission from the valence bands or core levels to vacuum. For photon energies less than $E_{\mathrm{g}}$ but greater than about twice the longitudinal optical phonon energy the absorption is relatively weak, resulting primarily from interactions with free carriers, electronic levels within the bandgap, localized vibrational modes due to impurities, or defects such as precipitates. Finally, for sufficiently low photon energies the absorption again increases due to photonphonon interactions.

The absorption is so intense at above-bandgap energies, with absorption coefficients generally exceeding $10^{4} \mathrm{~cm}^{-1}$, that transmission measurements are impracticable. Therefore reflectance techniques are used to elucidate the details of the valence and conduction band structures. Figure 14 shows the energy band

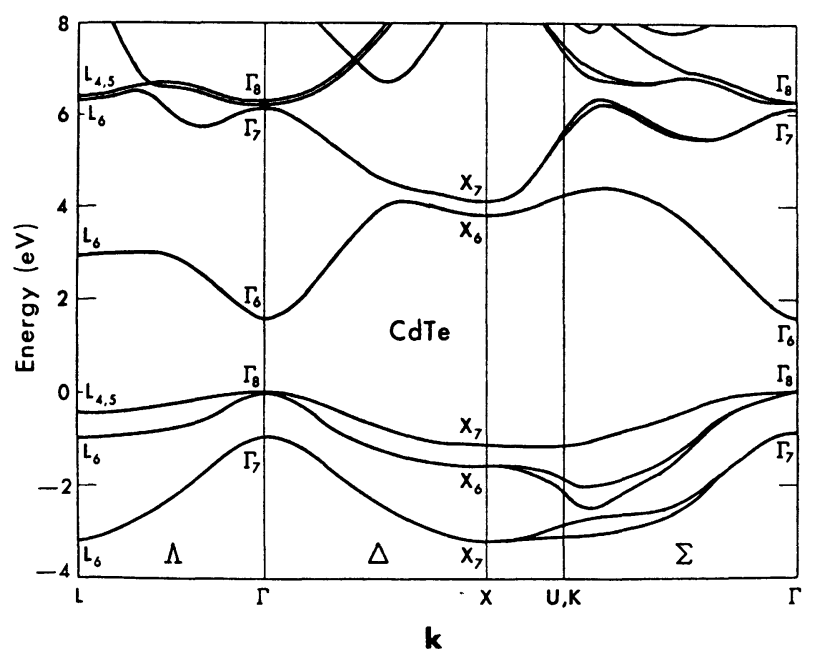

Fig. 14. - Calculated energy band structure of CdTe (Chadi et al., Ref. [34]).

structure of CdTe calculated by Chadi et al. [34] who used the empirical pseudopotential method to fit their reflectance data as well as other experimental results. As in other II-VI semiconductors with the zincblende or wurtzite structure, the lowest conduction band edge and highest valence band edge are both at $\Gamma$, so that the energy gap is direct. The bandgap is $1.606 \mathrm{eV}$ at liquid helium temperatures, and the spin-orbit splitting between the valence bands at $\Gamma$ is $0.91 \mathrm{eV}$. The secondlowest conduction band edge is located at the L-point, $1.35 \mathrm{eV}$ above the lowest. 
The degree of agreement between the calculated band structure and experimental data is illustrated by figure 15, which compares the reflectance calculated from the band structure with the experimental values

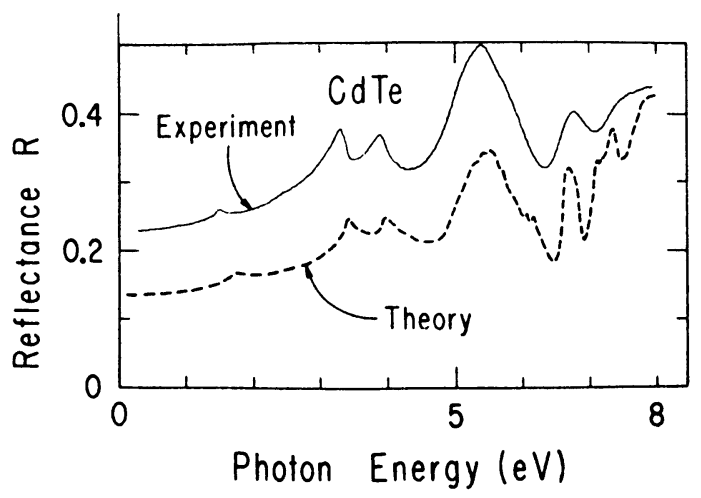

Fig. 15. - Experimental and theoretical curves for reflectance of CdTe vs photon energy (Freeouf, Ref. [35]).

measured at $300 \mathrm{~K}$ by Freeouf [35], who used a tungsten source at energies below $4.5 \mathrm{eV}$ and synchrotron radiation at higher energies. The theoretical curve closely reproduces the structure in the experimental curve, but its absolute magnitude is considerably lower.

The energy gaps of the II-VI compounds at liquid helium temperatures, together with the spin-orbit splittings of the valence bands at $\Gamma$, are summarized in table I. The energy gap of CdTe is the lowest for any of the compounds except $\mathrm{HgSe}$ and $\mathrm{HgTe}$, which are semimetals with zero or possibly negative energy gaps.

For a direct-gap semiconductor, the optical absorption coefficient decreases abruptly when the photon energy is reduced below $E_{\mathrm{g}}$. Figure 16 shows the absorption edge data obtained by Marple [36] at several temperatures for single-crystal samples that were first measured after being mechanically polished, then chemically polished and remeasured. These results show that mechanical damage significantly increases the lower absorption coefficients and leads to marked curvature of the absorption edge. This effect probably

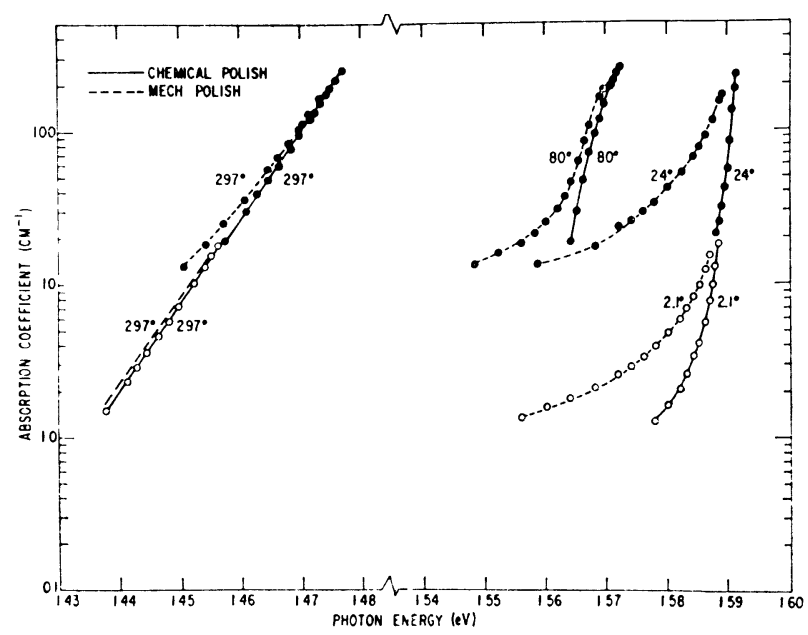

Fig. 16. - Optical absorption edge of CdTe vs temperature (Marple, Ref. [36]).

explains why early workers interpreted their data as evidence for an indirect energy gap in CdTe.

Figure 16 also shows that $E_{\mathrm{g}}$ for CdTe shifts to lower values with increasing temperature, the temperature dependence exhibited by most semiconductors. This shift is shown more clearly by Marple's complete data between 2 and $177 \mathrm{~K}$, as given in figure 17 . Because of the complexities of the absorption process, which involves phonon absorption and exciton formation, these data cannot be used for an accurate determination of the temperature dependence of $E_{\mathrm{g}}$. Up to about $150 \mathrm{~K}$, however, this dependence can be determined from reflectance and piezoreflectance spectra, which exhibit sharp structure that makes it possible to evaluate the exciton energy and therefore $E_{\mathrm{g}}$. The reflectance data of Thomas [37] and of Marple [38] show that as the temperature is increased from liquid helium temperature $E_{\mathrm{g}}$ decreases very slowly up to about $20 \mathrm{~K}$, then begins to decrease more rapidly, and between 80 and $150 \mathrm{~K}$ decreases linearly at the rate of $-3.5 \times 10^{-4} \mathrm{eV} \mathrm{K}^{-1}$. Extrapolation to $300 \mathrm{~K}$ gives $E_{\mathrm{g}}=1520 \mathrm{eV}$, in rather good agreement wit the value of $1.529 \mathrm{eV}$ obtained by Camassel et al. [39] by extra-

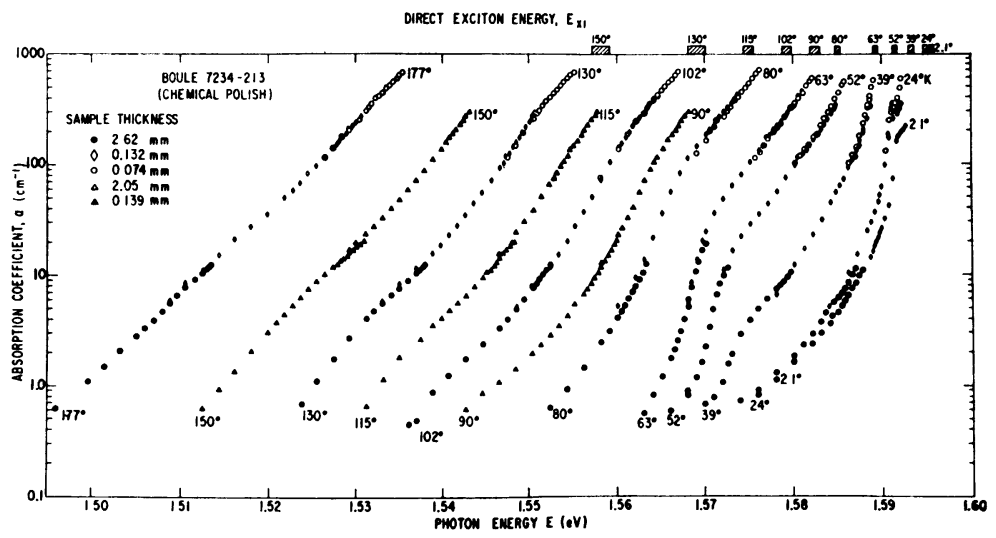

Fig. 17. - Optical absorption edge of CdTe vs temperature (Marple, Ref. [36]). 
polating their piezoreflectance results for the interval between 77 and $145 \mathrm{~K}$. According to Loferski's theoretical calculations [40], an energy gap of $1.52 \mathrm{eV}$ is very close to the value that can potentially yield the maximum possible efficiency for the conversion of solar radiation to electric power by means of semiconductor photovoltaic solar cells.

Electroreflectance techniques have been used by Babonas, Bendoryus and Shileika [41] and by Melz and Ortenburger [42] to determine the effect of hydrostatic pressure on the energy gap and spin-orbit splitting at $\Gamma$ for CdTe. Their results are in good agreement. For the pressure coefficient of $E_{\mathrm{g}}$ at room temperature they obtained $7.9 \times 10^{-6}$ and $8.3 \times 10^{-6} \mathrm{eV} / \mathrm{bar}$, respectively, and for the pressure coefficient of the spin-orbit splitting they obtained $0.8 \times 10^{-6} \mathrm{eV} /$ bar at $300 \mathrm{~K}$ and $0.7 \times 10^{-6} \mathrm{eV} / \mathrm{bar}$ at $77 \mathrm{~K}$, respectively.

For photon energies between the absorption edge and the onset of lattice phonon absorption - corresponding to wavelengths between about 0.9 and $30 \mu \mathrm{m}$ - the optical absorption of CdTe results primarily from the interaction between photons and various types of defects, if free carriers are regarded as electronic defects. Figure 18 shows the data of Strauss

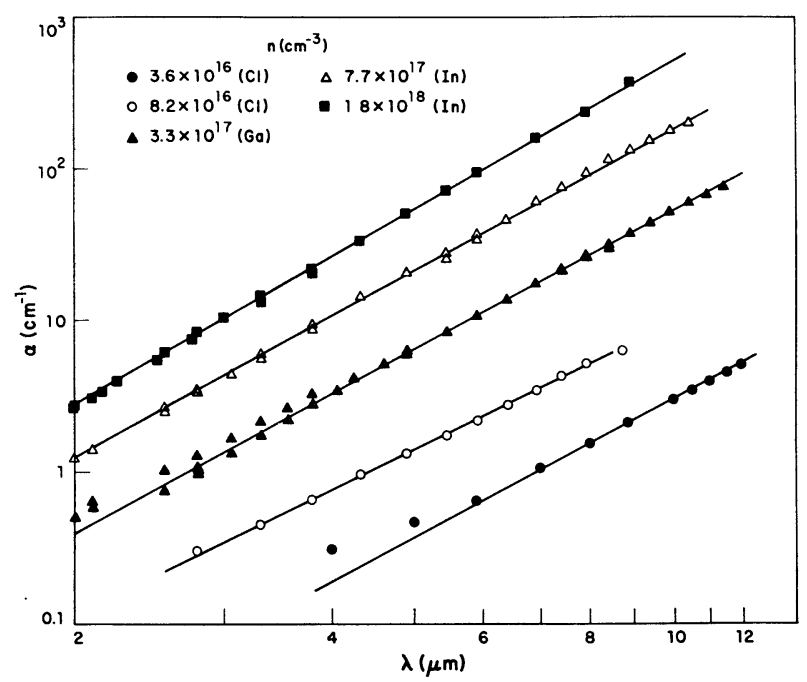

Fig. 18. - Free-carrier absorption of n-type CdTe at $300 \mathrm{~K}$ (Strauss and Iseler, Ref. [43]).

and Iseler [43] for the free-carrier absorption as a function of wavelength $\lambda$ measured at $300 \mathrm{~K}$ for singlecrystal n-type samples with electron concentrations between $3.6 \times 10^{16}$ and $1.8 \times 10^{18} \mathrm{~cm}^{-3}$. For a given concentration, the absorption coefficient exhibits the $\lambda^{\mathrm{m}}$ dependence characteristic of intraband free-carrier absorption, with values of $\mathrm{m}$ ranging from 2.7 to 3.4 rather than the classical Drude square-law dependence. The absorption cross section at $10.6 \mu \mathrm{m}$, the wavelength of the $\mathrm{CO}_{2}$ laser, is $1.0 \times 10^{-16} \mathrm{~cm}^{2}$ for the lowest concentration sample and increases to $3.5 \times 10^{-16} \mathrm{~cm}^{2}$ for the highest concentration sample.
Jensen [44] has obtained a very good theoretical fit, without using any adjustable parameters, to the data for concentrations of $1.4 \times 10^{17} \mathrm{~cm}^{-3}$ and below. According to her calculations, in this concentration range polar optical mode scattering is the predominant scattering mechanism, while ionized impurity scattering makes a very small contribution.

The optical absorption of p-type CdTe samples at photon energies less than $E_{\mathbf{g}}$ has been measured by Vul et al. [45] and by Capek et al. [46]. Figure 19 shows

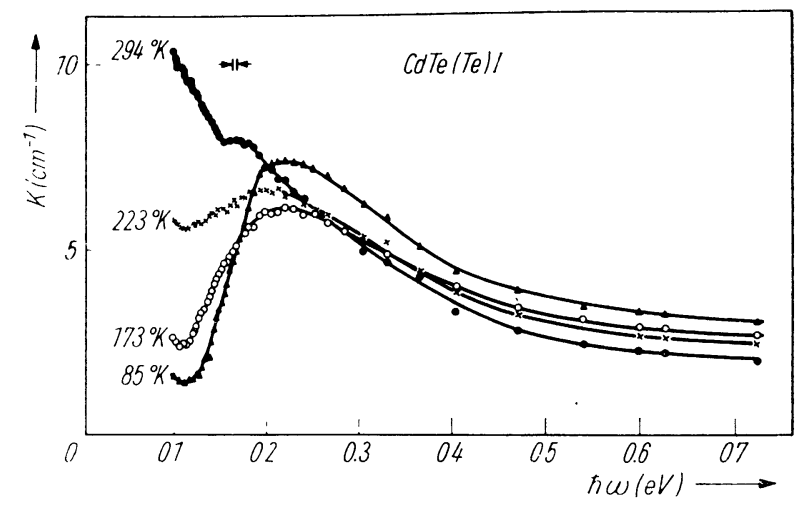

FIG. 19. - Optical absorption of p-type CdTe vs wavelength (Capek et al., Ref. [46]).

the results of Capek et al. for a nominally undoped sample grown in the presence of excess $\mathrm{Te}$, which had a hole concentration of $3.2 \times 10^{16} \mathrm{~cm}^{-3}$ at $300 \mathrm{~K}$ that decreased by several orders of magnitude on cooling to $80 \mathrm{~K}$. The absorption peak at about $0.2 \mathrm{eV}$, which is not strongly temperature dependent, is attributed to transitions from the valence band to an acceptor level, while the temperature-dependent absorption at lower energies is attributed to interband free-carrier transitions from the light-hole valence to the heavy-hole valence band. At room temperature the absorption cross section at $10.6 \mu \mathrm{m}(0.12 \mathrm{eV})$ is about $3 \times 10^{-16} \mathrm{~cm}^{2}$, and similar values were found for other samples by both Capek et al. [46] and Vul et al. [45] In P-doped samples the former authors observed absorption peaks at 0.07 and $1.07 \mathrm{eV}$ that they attributed to transitions to the $P$ acceptor level from the doubly-degenerate and split-off valence bands, respectively.

For sufficiently small photon energies, optical absorption due to interactions with the lattice phonons becomes significant. The onset of lattice absorption in CdTe is shown by figure 20. This figure gives the data of Deutsch [47] for the absorption coefficients of CdTe, $\mathrm{ZnSe}$, and $\mathrm{GaAs}$ as a function of the reduced frequency, defined as the ratio of photon frequency $\omega$ to the longitudinal optical phonon frequency $\omega_{10}$, which is $168 \mathrm{~cm}^{-1}$ for CdTe. According to the CdTe data, as represented by the solid curve, the absorption coefficient is $0.01 \mathrm{~cm}^{-1}$ at about $21 \mu \mathrm{m}$.

The point shown in figure 20 at $6 \times 10^{-4} \mathrm{~cm}^{-1}$ 


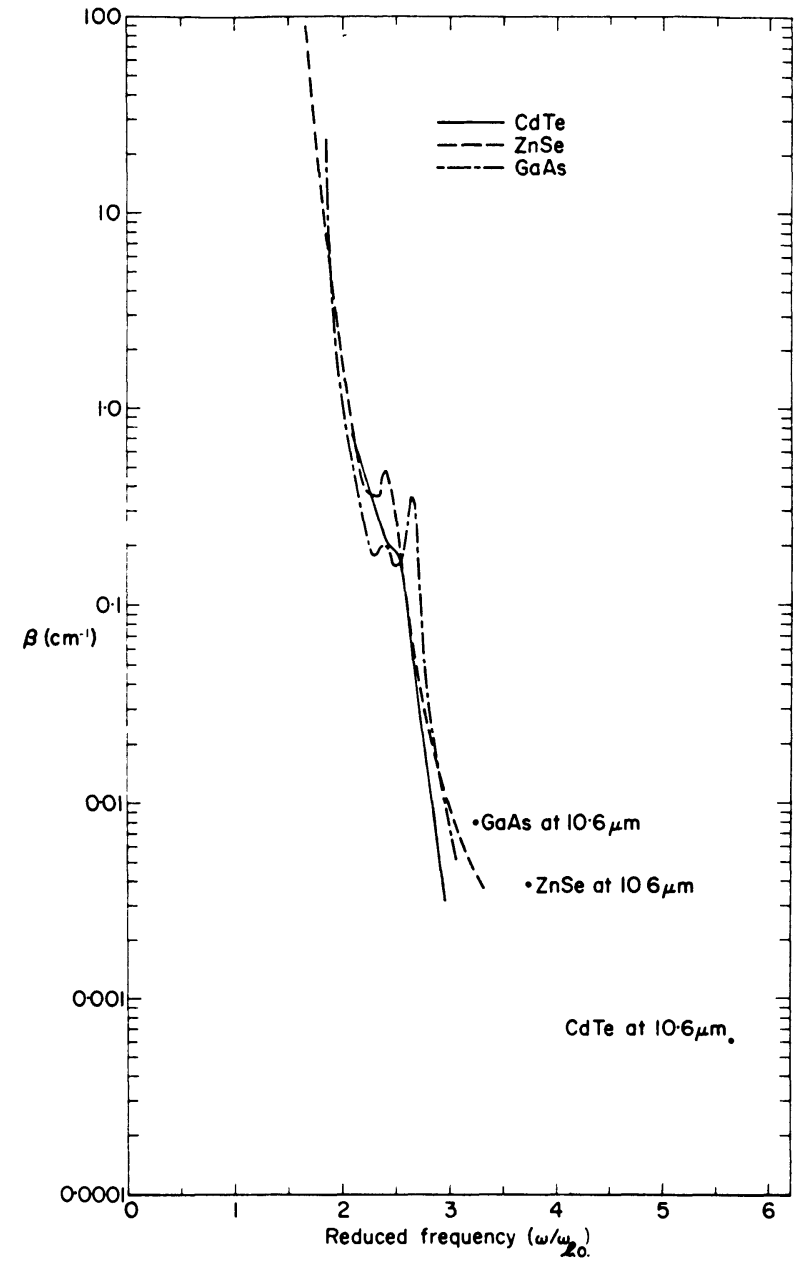

Fig. 20. - Lattice absorption of CdTe vs reduced photon frequency (Deutsch, Ref. [47]).

represents the lowest absorption coefficient at $10.6 \mu \mathrm{m}$ that had been observed for CdTe at the time Deutsch submitted his paper. To the best of my knowledge, the lowest reported value is $2.5 \times 10^{-4} \mathrm{~cm}^{-1}$. It is obvious that extrapolation of the linear portion of the CdTe curve would yield an absorption coefficient at $10.6 \mu \mathrm{m}$ many orders of magnitude below $10^{-5} \mathrm{~cm}^{-1}$, indicating that lattice absorption is not the mechanism that is currently setting the lower limit on the transmission of $\mathrm{CdTe}$ at this wavelength. It also appears that freecarrier absorption is not the limiting mechanism, since several groups have reported the preparation of semiinsulating CdTe with hole concentrations of less than $10^{10} \mathrm{~cm}^{-3}$, which would give absorption coefficients well below $10^{-5} \mathrm{~cm}^{-1}$ if the measured free-carrier cross sections were maintained. Instead, it seems probable that microstructural defects such as precipitates, dislocations, and stacking faults are responsible for the absorption at $10.6 \mu \mathrm{m}$. In a study utilizing transmission electron microscopy. Magee, Peng, and Bean [48] have shown a correlation between the concentration of such defects and the absorption coefficient for coefficients down to $10^{-4} \mathrm{~cm}^{-1}$.
The absorption data for CdTe plotted in figure 20 extend only to about $330 \mathrm{~cm}^{-1}$, corresponding to $30 \mu \mathrm{m}$. As the photon energy is decreased still further, the absorption becomes structured and much more intense. Figure 21 shows the transmittance data
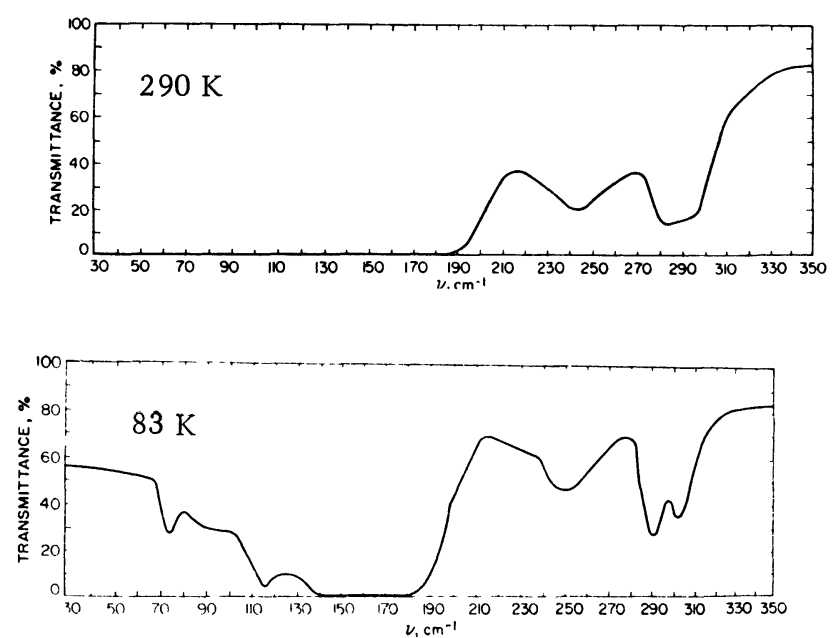

FIG. 21. - Lattice absorption of CdTe vs photon frequency (Stafsudd et al., Ref. [49]).

obtained by Stafsudd, Haak, and Radisavljevic [49] for a sample $0.45 \mathrm{~mm}$ thick over the frequency range from 30 to $350 \mathrm{~cm}^{-1}$, corresponding to wavelengths from about 28 to $330 \mu \mathrm{m}$. The upper curve was measured at $290 \mathrm{~K}$, the lower at $83 \mathrm{~K}$. The strongest absorption occurs at the fundamental of the transverse optical mode, $141 \mathrm{~cm}^{-1}$, while the other peaks are twophonon combination bands. Table $\mathrm{V}$ lists the 6 strongest peaks and the phonon assignments given by Danielewicz and Coleman [50].

TABLE V

Strongest lattice absorptions in $\mathrm{CdTe}\left({ }^{a}\right)$

$\begin{array}{ccc}\begin{array}{c}\text { Approximate } \\ \text { frequency } \\ \left(\mathrm{cm}^{-1}\right)\end{array} & \begin{array}{c}\text { Approximate } \\ \text { wavelength } \\ (\mu \mathrm{m})\end{array} & \begin{array}{c}\text { Phonon } \\ \text { assignment }\end{array} \\ 72 & - & - \\ 115 & 138 & 2 \text { TA } \\ 141 & 88 & \text { LO - TA } \\ 250 & 70 & \text { TO } \\ 290 & 40 & \text { LO + LA } \\ 300 & 34.5 & \text { LO + TO }\end{array}$

(a) Ref. [50].

Figure 22 shows the data of Manabe, Mitsuishi, and Yoshinaga [51] for the reflectivity of CdTe and several other II-VI compounds between 20 and $100 \mu \mathrm{m}$. The characteristic restrahlen band associated with the transverse optical phonon has its peak at about $67 \mu \mathrm{m}$ 


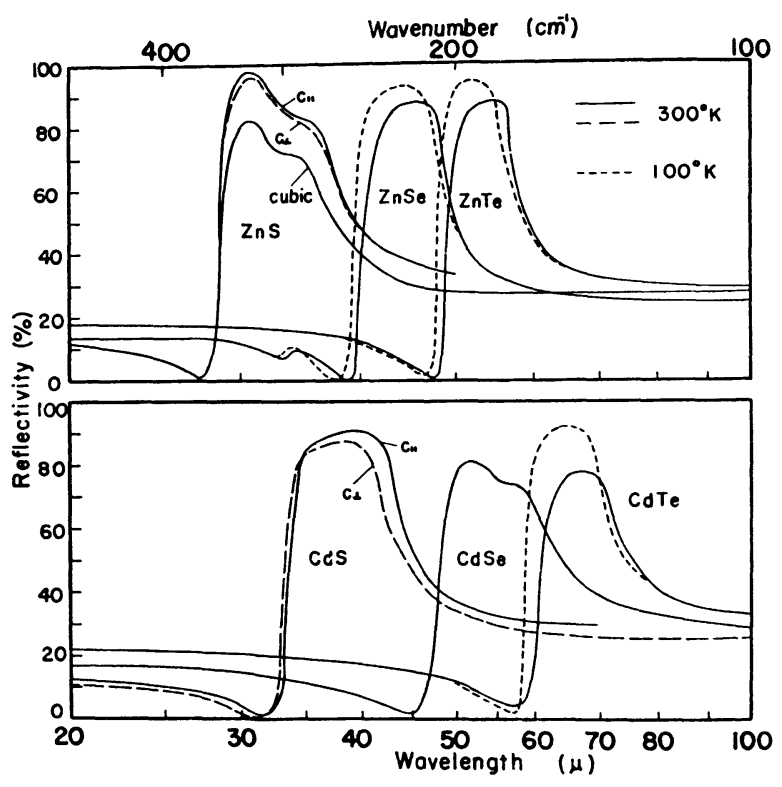

Fig. 22. - Far-infrared reflectivity of IIA-VIB compounds (Manabe et al., Ref. [51]).

for CdTe at $300 \mathrm{~K}$, the longest wavelength for any of the compounds investigated. Numerous authors have analyzed reflectivity data for CdTe in terms of a classical oscillator model to obtain values for the static and high-frequency dielectric constants. These constants are listed in table VI, together with some other

\section{TABLE VI}

\section{Some optical properties of $\mathrm{CdTe}$ at $300 \mathrm{~K}$}

$\begin{array}{lc}\text { Refractive index, } n_{0}, \text { at } 10.6 \mu \mathrm{m}\left(^{(a)}\right. & 2.672 \\ \text { Reflectivity at } 10.6 \mu \mathrm{m}\left(^{b}\right) & 0.207 \\ (1 / n) \mathrm{d} n / \mathrm{d} T\left(\mathrm{~K}^{-1}\right)\left(^{(}\right) & (4.4 \pm 0.03) \times 10^{-5} \\ \begin{array}{l}\text { Dielectric constants }\left(^{d}\right) \\ \quad \text { Optical, } \varepsilon_{\infty}\end{array} & 7.15 \pm 0.05 \\ \quad \text { Static, } \varepsilon_{0} & 10.3 \pm 0.1 \\ \text { Damping constant, } \Gamma\left(\mathrm{cm}^{-1}\right)\left(^{d}\right) & 7.5 \pm 1.2 \\ \text { Elastooptic coefficients }\left({ }^{e}\right) & \\ \quad p_{11} & -0.152 \pm 0.013 \\ p_{12} & -0.017 \pm 0.011 \\ p_{44} & -0.057 \pm 0.007\end{array}$

(a) See Ref. [50].

$\left({ }^{b}\right)$ Calculated from $n_{0}$.

(c) Kiefer, J. E. and Yariv, A., Appl. Phys. Lett. 15 (1969) 26.

(d) See Refs. [29] and [50].

(e) WeIL, R. and SUN, M. J., Proc. Int. Sym. on Cadmium Telluride, Strasbourg, 1971.

optical properties of CdTe, while table VII gives values of the electrooptic coefficient $r_{41}$ and the nonlinear susceptibility. Since the electrooptic coefficient of $\mathrm{CdTe}$ at $10.6 \mu \mathrm{m}$ is about 4 times that of GaAs, while its refractive index is about $20 \%$ lower, the figure of merit for electrooptic modulation, $n_{0}^{3} r_{41}$, is about twice as high for CdTe as for GaAs.
TABLE VII

\section{Electrooptic coefficient and nonlinear susceptibility of $\mathrm{CdTe}$}

Electrooptic coefficient, $r_{41}$

$$
\begin{array}{ll}
(\mathrm{m} / \mathrm{V})\left({ }^{a}\right) & \\
\text { At } 10.6 \mu \mathrm{m} & 5.2 \times 10^{-12} \\
\text { At } 28.0 \mu \mathrm{m} & 5.2 \times 10^{-12} \\
n_{0}^{3} r_{41}(\mathrm{~m} / \mathrm{V}) & \\
\text { At } 10.6 \mu \mathrm{m}\left(^{b}\right) & 1.0 \times 10^{-10} \\
\text { At } 28.0 \mu \mathrm{m}\left(^{c}\right) & 8.5 \times 10^{-11}
\end{array}
$$

Nonlinear susceptibility, $d_{14}$ $(\mathrm{m} / \mathrm{V})$

$$
\begin{array}{lr}
\text { At } 10.6 \mu \mathrm{m}\left({ }^{d}\right) & (16.8 \pm 6.3) \times 10^{-11} \\
\text { At } 28.0 \mu \mathrm{m}\left({ }^{e}\right) & (5.9 \pm 2.4) \times 10^{-11}
\end{array}
$$

(a) Calculated from measured values of $n_{0}^{3} r_{41}$ and $n_{0}$.

$\left({ }^{b}\right)$ Kiffer, E., Nussmeier, T. A. and Goodwin, F. E., IEEE J. Quantum Electron. QE-8 (1972) 173.

(c) Akitt, D. P., Johnson, C. J. and Coleman, P. D., IEEE J. Quantum Electron. QE-6 (1970) 496.

(d) Patel, C. K. N., Phys. Rev. Lett. 16 (1966) 613.

(e) Sherman, G. H. and Coleman, P. D., J. Appl. Phys. 44 (1973) 238

5. Electrical properties. - We shall now turn our attention to the electrical properties of CdTe, the last general class of physical properties that will be reviewed in this paper. Like the optical properties, they are ultimately limited by the electronic band structure, which determines the intrinsic carrier concentration, and by the lattice vibration modes, which set upper limits on the electron and hole mobilities. However, the electrical properties are influenced to a much greater extent by impurities, native defects, and the interactions between them.

A semiconductor's intrinsic carrier concentration $n_{\mathbf{i}}$ is determined by three band-structure parameters : the energy gap $E_{\mathrm{g}}$ and the density-of-states effective masses $m_{\mathrm{n}}^{*} / m_{0}$ and $m_{\mathrm{p}}^{*} / m_{0}$ for electrons and holes, respectively. We have used the standard theoretical expression to calculate values of $n_{\mathbf{i}}$ for temperatures between 300 and $1200 \mathrm{~K}$ by adopting the following values for these parameters :

$$
E_{\mathrm{g}}(\mathrm{eV})=1.622-3.5 \times 10^{-4} \mathrm{~T},
$$

$m_{\mathrm{n}}^{*} / m_{0}=0.1$, and $m_{\mathrm{p}}^{*} / m_{0}=0.8$. The expression for $E_{\mathrm{g}}$ is based on the exciton reflectance data mentioned previously, the electron effective mass approximates the value of 0.0963 obtained by Mears and Stradling [52] from cyclotron resonance data, and the hole effective mass is the heavy-hole mass value that Kranzer [53] found to give the best fit between his theoretical mobility calculations and the experimental data. This choice of parameters leads to the following equation for the intrinsic carrier concentration :

$$
n_{\mathrm{i}}^{2}=\left(3.066 \times 10^{31}\right) \mathrm{T}^{3} \exp \left(-1.882 \times 10^{4} / \mathrm{T}\right) .
$$


According to this expression, $n_{\mathrm{i}}$ is only $6.9 \times 10^{5} \mathrm{~cm}^{-3}$ at $300 \mathrm{~K}$ and only $1.5 \times 10^{14} \mathrm{~cm}^{-3}$ even at $700 \mathrm{~K}$. It is clear that intrinsic carriers do not make an important contribution to conduction at room temperature in any CdTe samples so far prepared, since the lowest roomtemperature carrier concentration of which I am aware is $8.3 \times 10^{7} \mathrm{~cm}^{-3}$, as reported by Alekseenko et al. [54] for a p-type sample. Furthermore, because $n_{\mathrm{i}}$ is so low, mixed conduction due to both electrons and holes does not occur at room temperature. Thus even in the sample just mentioned the electron concentration is so low that less than $0.1 \%$ of the current is carried by electrons, in spite of the fact that they are about 10 times as mobile as holes.

The preceding discussion shows that the current carriers responsible for conduction in $\mathrm{CdTe}$ at room temperature and below must be generated by the ionization of impurities, native defects, or complexes between them. Returning to figure 1 , the portion of the periodic table shown previously, we see most of the impurity elements that have been identified as electrically active in CdTe. Their observed activity as acceptors or donors can be explained by assuming that elements in the columns adjacent to $\mathrm{Cd}$ in the table substitute for $\mathrm{Cd}$ atoms in the lattice and those adjacent to Te substitute for $\mathrm{Te}$, then applying the usual rule that a substitutional impurity is a donor or acceptor depending on whether it has more or less valence electrons than the atom it replaces. Since elements in adjacent columns differ by one valence electron, all the impurities considered here should be singly ionized acceptors or donors. (Since the electrical properties of these elements were reviewed at the 1971 Symposium [55], I shall refer explicitly only to investigations reported since then.)

Thus the Group V elements $\mathrm{P}, \mathrm{As}$, and $\mathrm{Sb}$ are acceptors, presumably substituting for Te. Gu et al. [56] have reported the growth from the melt of P-doped crystals with room-temperature hole concentrations of $5 \times 10^{16}$ to $6 \times 10^{17} \mathrm{~cm}^{-3}$ and mobilities of 24 to $39 \mathrm{~cm}^{2} \mathrm{~V}^{-1} \mathrm{~s}^{-1}$. They measured ionization energies between 0.036 and $0.060 \mathrm{eV}$, compared with an earlier value of about $0.05 \mathrm{eV}$ obtained for samples with hole concentrations a little above $10^{16} \mathrm{~cm}^{-3}$. The acceptor behavior of As is demonstrated by its ability to convert n-type samples to p-type by ion implantation, but no measurements of its ionization energy have been reported. Höschl and Kubalkova [57] state that highly conducting p-type CdTe can be prepared by Sb doping but give no details.

The Group IB elements $\mathrm{Cu}, \mathrm{Ag}$, and $\mathrm{Au}$ are also acceptors, presumably substituting for $\mathrm{Cd}$, with ionization energies reported in the range from 0.3 to $0.4 \mathrm{eV}$. Popova and Polivka [58] have described the preparation of samples with room-temperature hole concentrations as high as $1 \times 10^{18} \mathrm{~cm}^{-3}$ and conductivities as high as $90 \Omega^{-1} \mathrm{~cm}^{-1}$, the highest so far reported for p-type $\mathrm{CdTe}$, by means of $\mathrm{Cu}$ diffusion. They do not give ionization energies, and there appear to be inconsistencies among their tabulated values for conductivity, carrier concentration, and mobility. On the basis of Rutherford backscattering experiments Akutagawa et al. [59] report that, depending on annealing conditions, between 50 and $85 \%$ of the $\mathrm{Au}$ present in CdTe is substituted on $\mathrm{Cd}$ sites, with the rest present either interstitially or in the form of precipitates.

The Group IA elements $\mathrm{Na}$ and $\mathrm{Li}$, which are not shown in figure 1, are also acceptors that presumably substitute for $\mathrm{Cd}$. Like $\mathbf{P}$ they are shallow acceptors, with reported ionization energies of 0.028 and $0.034 \mathrm{eV}$, respectively, for samples with room-temperature hole concentrations close to $10^{17} \mathrm{~cm}^{-3}$.

The two types of donor impurities that have been identified in CdTe are both shown on figure 1 : the Group III elements $\mathrm{Al}, \mathrm{Ga}$, and In, which presumably substitute for $\mathrm{Cd}$, and the Group VII halogens $\mathrm{Cl}, \mathrm{Br}$ and I, which presumably substitute for Te. The highest room-temperature carrier concentration that can be obtained by doping with $\mathrm{Ga}$ is about $4 \times 10^{17}$ while concentrations of about $2 \times 10^{18} \mathrm{~cm}^{-3}$ can be obtained with the other elements. It has not been possible to determine ionization energies of these impurities because carrier freeze-out with decreasing temperature has not been observed for samples to which a dopant has been added in a sufficient quantity to be identified as the dominant donor. The absence of freeze-out results because the ionization energy of an impurity in a semiconductor decreases as its concentration increases, and shallow donor levels eventually merge with the conduction band at sufficiently high concentrations. This effect is shown by figure 23 , which

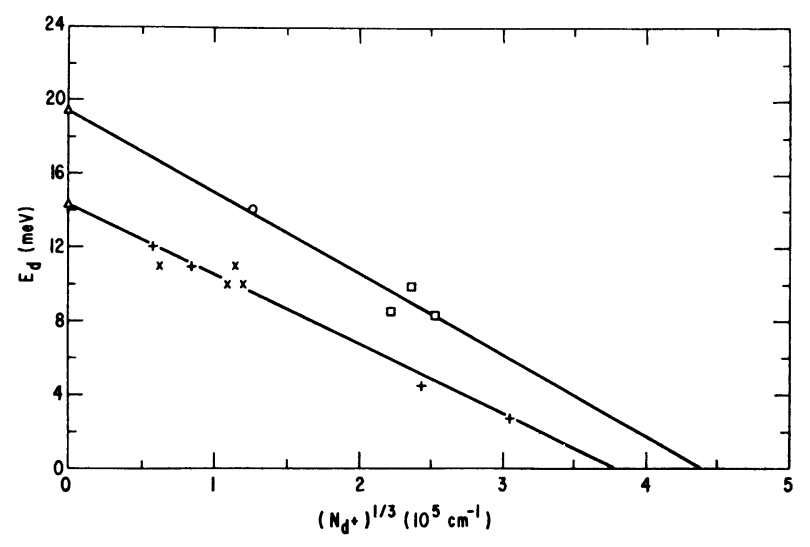

FIG. 23. - Donor ionization energy vs ionized donor concentration for CdS (upper line) and CdTe (lower line) (Woodbury and Aven, Ref. [60]).

is a plot given by Woodbury and Aven [60] for the donor ionization energy $E_{\mathrm{d}}$ in CdSe (upper line) and $\mathrm{CdTe}$ (lower line) as a function of the ionized donor concentration $\mathrm{N}_{\mathrm{d}+}$. The points for CdTe were obtained by analysis of the Hall coefficient vs temperature data of Agrinskaya et al. [61] (crosses) for one nominally Aldoped and three nominally undoped samples and the data of Segall et al. [62] ( $x$ 's) for nominally undoped 
samples. The points are fit very well by a straight line whose intercept on the abscissa indicates that the ionization energy vanishes when $N_{d+}$ reaches $5 \times 10^{16} \mathrm{~cm}^{-3}$. The limiting ionization energy given by the intercept on the ordinate is $14.3 \mathrm{meV}$, the value for the donor ionization energy in high-purity samples obtained from the optical absorption data of Cohn, Larsen, and Lax [63]. This agrees with the value of $14.1 \mathrm{meV}$ calculated for hydrogenic donors in $\mathrm{CdTe}$, showing that the donors in high-purity CdTe are hydrogenic. It is therefore generally assumed that the Group III and Group VII donors in CdTe are also hydrogenic. On the basis of high-pressure and photoconductivity measurements it has been suggested by Iseler et al. [64] that $\mathrm{Ga}$, In, $\mathrm{Cl}$, and $\mathrm{Br}$ introduce nonhydrogenic levels associated with a higher conduction band, but it would be an understatement to say that this suggestion of so-called non- $\Gamma$ donors has not been widely accepted.

The purest samples of lightly compensated CdTe so far reported have been obtained by Triboulet and Marfaing [65] from single crystals grown by the vertical zone melting of ingots synthesized by the Bridgman method. The best of these samples have roomtemperature carrier concentrations between 1 and $5 \times 10^{13} \mathrm{~cm}^{-3}$ and resistivities of 100 to $400 \Omega . \mathrm{cm}$. Their low-temperature carrier mobilities, which will be described later, are the highest reported. It has been estimated that the total concentration of electrically active centers in these crystals is about $10^{14} \mathrm{~cm}^{-3}$.

Since we have mentioned that both hole and electron concentrations exceeding $10^{17} \mathrm{~cm}^{-3}$ can be obtained by doping CdTe with shallow acceptors and donors, respectively, it is appropriate to point out that CdTe is unique among the semiconducting II-VI compounds in its ability to exhibit both p-type and n-type bulk conductivity at relatively high levels. The conductivity types of the II-VI compounds are summarized in table I. The only one other than CdTe that can exhibit both conductivity types in bulk samples is the semimetal $\mathrm{HgTe}$, and because of the high ratio of electron to hole mobility and the high intrinsic carrier concentration, even at liquid helium temperature, hole concentrations of the order of $10^{19} \mathrm{~cm}^{-3}$ are required in order for more current to be carried by holes than by electrons. For $\mathrm{ZnSe}$, as indicated by placing the letter « $\mathrm{p}$ » in parentheses, there is fairly good evidence that thin p-type layers can be produced by diffusion of In followed by annealing in $\mathrm{Zn}$ vapor [66] and it has also been reported [67] that p-type material can be formed by $\mathrm{Li}$ doping or implantation.

The inability of the II-VI semiconductors other than CdTe to exhibit both p- and n-type conductivity is due to the formation of electrically active native point defects that are associated with deviations from the stoichiometric composition. In a II-VI compound, an excess of the metallic element can be incorporated most simply by means of metal interstitials or non-metal vacancies, while an excess of non-metal can be incorpo- rated by means of non-metal interstitials or metal vacancies. The defects associated with excess metal are generally donors and those associated with excess nonmetal are generally acceptors, although there is persuasive evidence for neutral interstitials in a number of the compounds. In those compounds that exhibit only n-type conductivity any impurities that would normally be acceptors are rendered ineffective by the presence of native donors. In addition, donor impurities are fully effective only at the metal-saturated boundary of the compound's homogeneity region; as the composition is made less metal-rich, as can be accomplished by equilibrating the material with metal vapor at pressures lower than the saturation pressure, the donors are compensated to an increasing extent by native acceptor defects. This process, known as selfcompensation, continues until the carrier concentration becomes very low and the resistivity correspondingly high. The analogous phenomena, in reverse, take place for the compounds that exhibit only p-type conductivity.

Although CdTe can exhibit both p- and n-type conductivity, like the other II-VI compounds its electrical properties are strongly affected by native defects, and in particular a very high degree of self-compensation is observed for samples that contain excess donor impurities. Before discussing such samples, however, we shall consider the properties of samples that contain few if any excess donor impurities. These properties are illustrated by figure 24 , which shows the carrier concen-

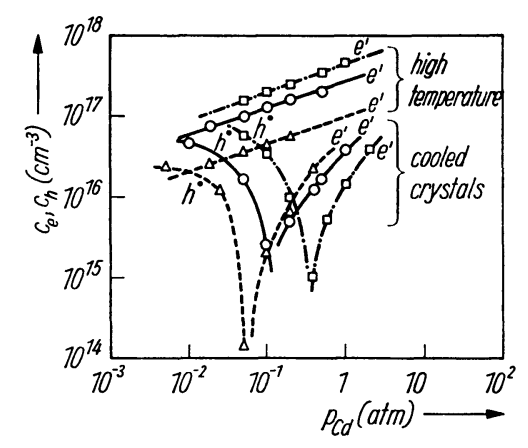

Fig. 24. - Carrier concentration of CdTe vs Cd pressure for samples measured in situ or after quenching to room temperature (Selim et al., Ref. [68]).

tration data reported by Selim, Swaminathan, and Kröger [68] for samples nominally doped with $5 \times 10^{16} \mathrm{~cm}^{-3}$ of $\mathrm{Cl}$ that were annealed at 700,800 , and $900^{\circ} \mathrm{C}$ under different pressures of $\mathrm{Cd}$ vapor. The straight lines labelled high temperature are isotherms obtained by in situ measurements made at each annealing temperature. The samples are all n-type, with electron concentrations that are proportional to $\mathrm{p}_{\mathrm{Cd}}^{1 / 3}$. This pressure dependence shows that the carriers are produced by the ionization of doubly-ionized native donors, but the data do not establish whether these donors are $\mathrm{Cd}$ interstitials or Te vacancies. After 
the samples were cooled to room temperature, those annealed at sufficiently high pressures remained n-type, while those annealed at lower pressures were found to be p-type. Selim et al. [68] attribute the holes in the p-type samples to native defects, while Smith [69] has explained similar data in terms of acceptor impurities. In any case, because of the steepness of the concentration-vs-pressure curves near the transition from nto p-type, it would not be feasible to control the annealing pressure well enough to obtain very low carrier concentrations.

Such low concentrations can be obtained quite readily, however, by utilizing self-compensation in donor-doped samples. The earliest reported example of this effect in CdTe is shown by figure 25 , which

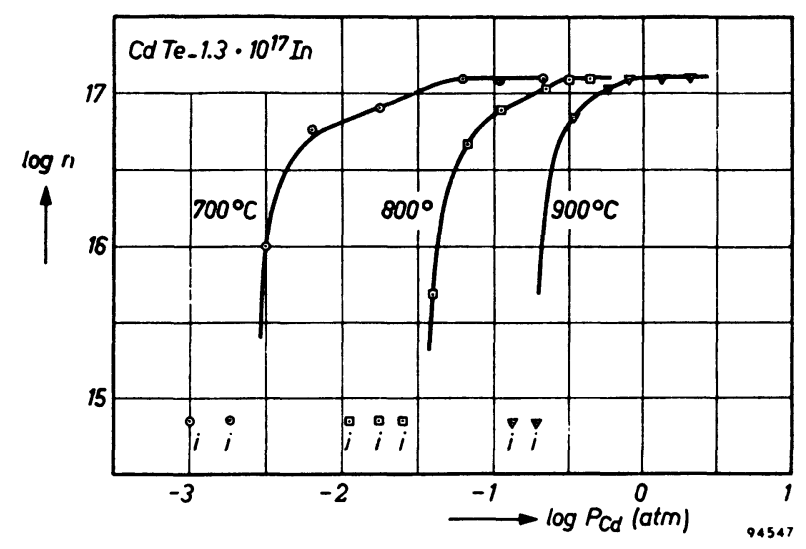

FIG. 25. - Carrier concentration of In-doped CdTe vs Cd pressure for samples measured after quenching to room temperature (de Nobel, Ref. [70]).

gives the data published by de Nobel [70] in 1959 for the carrier concentration measured at room temperature for samples doped with $1.3 \times 10^{17} \mathrm{~cm}^{-3}$ In that had been annealed at various $\mathrm{Cd}$ pressures at 700, 800, and $900{ }^{\circ} \mathrm{C}$. In each case, when the annealing pressure was reduced below a certain value the carrier concentration dropped abruptly to values too low for de Nobel to measure (represented by points marked «i $»)$, yielding resistivities of $10^{6}$ to $10^{7} \Omega . \mathrm{cm}$, and remaining this low no matter how much the $\mathrm{Cd}$ pressure was reduced. Similar results have been obtained for samples with donor impurity concentrations as high as $10^{18} \mathrm{~cm}^{-3}$.

Self-compensation has been extensively employed to obtain CdTe samples with carrier concentrations low enough to give the high electrical resistivity needed for $\gamma$-ray detectors and the high optical transmission needed for electrooptic modulators and infrared windows. Gentile et al. [71] have described a technique for preparing highly transparent samples by annealing material doped with about $2 \times 10^{17} \mathrm{~cm}^{-3}$ In over a temperature range down to $700^{\circ} \mathrm{C}$ at $\mathrm{Te}_{2}$ pressures somewhat lower than the saturation pressure. Several other groups have used growth from Te-rich solutions, which yields crystals that are initially Te- saturated at the growth temperature, to establish the deviation from stoichiometry needed for self-compensation. Höschl et al. [72] grew Cl-doped crystals by a technique similar to the Bridgman method, while Wald and Bell [73] and Triboulet et al. [74] both used the traveling heater method, the former with Cl-doped starting material and the latter with starting material that had been purified by vertical zone melting. Alekseenko et al. [54] also used the traveling heater method but doped the crystals with $\mathrm{Cl}$ after growth. As mentioned above, they report a carrier concentration of $8 \times 10^{7} \mathrm{~cm}^{-3}$, which gave a resistivity of $3 \times 10^{11} \Omega . \mathrm{cm}$. All the $\mathrm{Cl}$-doped semi-insulating crystals grown from Te-rich solutions are p-type.

Numerous localized electronic levels lying within the energy gap of $\mathrm{CdTe}$, many of which undoubtedly involve native defects, have been detected by applying various characterization techniques to high-resistivity CdTe. Since the native defects and the mechanism of self-compensation will be reviewed later in the Symposium by Professor Kröger and Dr. Marfaing, it will not be necessary for this paper to discuss the details of the identification of the localized levels and their influence on the electrical properties of CdTe. It is appropriate, however, to point out the essential role played by deep levels in obtaining semi-insulating properties in any semiconductor. As shown schematically in figure 26,

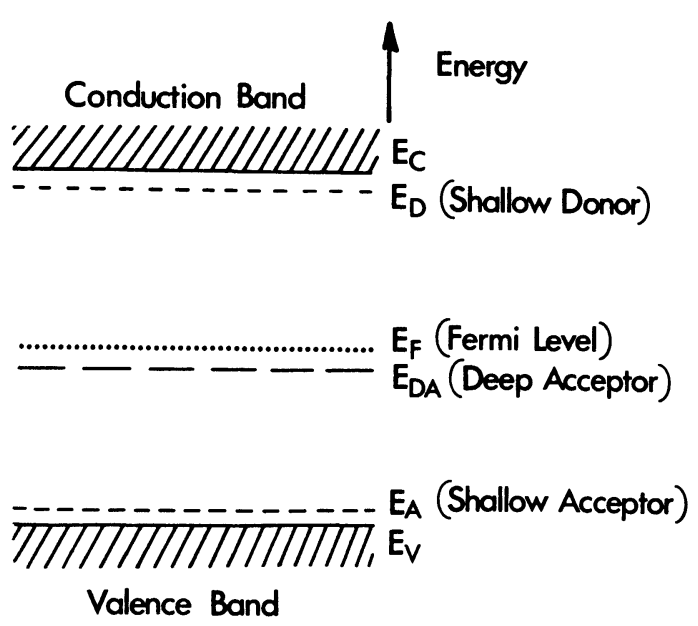

FIG. 26. - Deep-acceptor model for production of semiinsulating, donor-doped semiconductor (Thompson, Ref. [75]).

which is actually taken from a paper by Thompson [75] that discusses the preparation of semi-insulating GaAs, for a material that contains an excess of shallow donors over shallow acceptors the deep levels must be acceptors. When the concentration of deep acceptors becomes high enough to exceed the difference between the shallow donor and acceptor concentrations, the Fermi level will fall abruptly from the vicinity of the shallow donor level to the vicinity of the deep acceptor level, where it remains pinned to yield semi-insulating materials over a wide range of deep acceptor concentrations. 
The energies of some of the prominent levels that have been reported to exist within the energy gap of CdTe are shown in figure 27, which reproduces a diagram given by Siffert et al. [76]. The level shown

CONDUCTION BAND
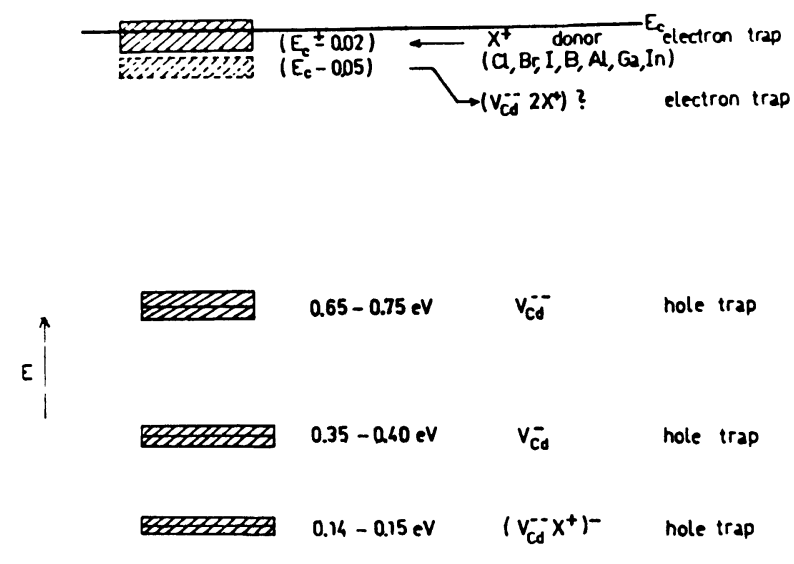

VALENCE BAND

FIG. 27. - Some localized levels within the energy gap of CdTe (Siffert et al., Ref. [76]).

at $0.65-0.75 \mathrm{eV}$ corresponds to the activation energy observed by various workers in resistivity vs temperature measurements on high-resistivity samples. It will be interesting to learn whether the identifications proposed by Siffert et al. for the defects responsible for these levels will be generally accepted.

To complete this discussion of the electrical properties of CdTe, we shall now consider the Hall and drift mobilities of electrons and holes. Figure 28 shows the curves of Hall mobility vs temperature reported by Triboulet and Marfaing [65] for n-type samples cut at four locations from the head (curve 1) to the tail

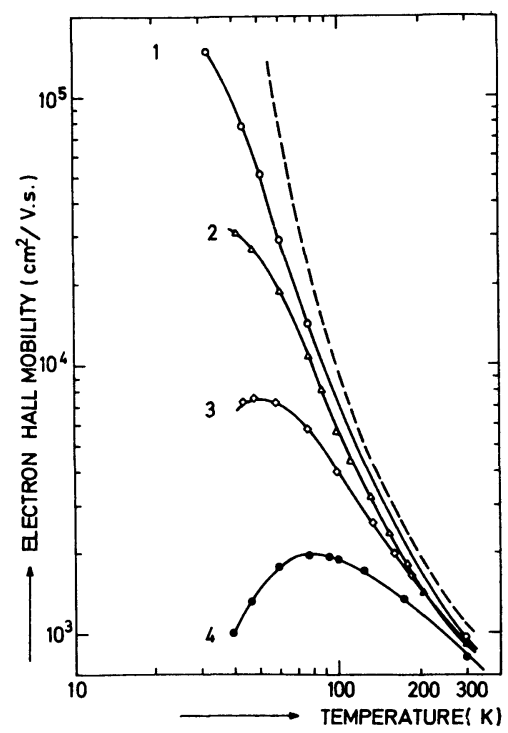

Fig. 28. - Hall mobility vs temperature for electrons in CdTe (Triboulet and Marfaing, Ref. [65]). (curve 4) of ingots they prepared by vertical zone refining. The impurity content increases systematically from head to tail, as shown by the reduction in mobility at low temperatures due to ionized impurity scattering. The mobility measured for the purest sample at $32 \mathrm{~K}$ is $1.46 \times 10^{5} \mathrm{~cm}^{2} \mathrm{~V}^{-1} \mathrm{~s}^{-1}$, the highest reported for $\mathrm{CdTe}$. The data for this sample are in good agreement with the theoretical calculations of Segall, Lorenz, and Halsted [62] represented by the dashed curve, and in even better agreement with the later calculation of Rode [77]. Both theoretical treatments show that polar optical mode scattering is the principal lattice scattering mechanism over the temperature range shown. The mobility measured for sample 1 at $300 \mathrm{~K}$ was $950 \mathrm{~cm}^{2} \mathrm{~V}^{-1} \mathrm{~s}^{-1}$, while other samples that had somewhat lower mobilities at low temperature had mobilities up to $1100 \mathrm{~cm}^{2} \mathrm{~V}^{-1} \mathrm{~s}^{-1}$ at $300 \mathrm{~K}$.

Figure 29 reproduces a figure given by Triboulet et al. [74] for the Hall mobility of holes in CdTe as a

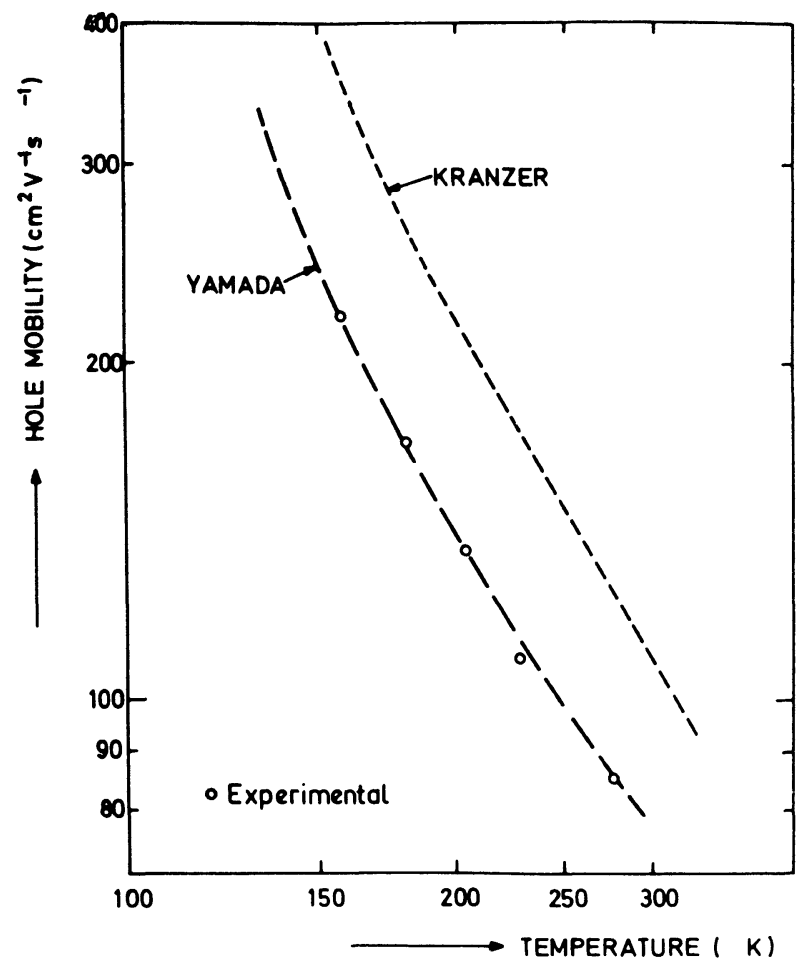

FIG. 29. - Hall mobility vs temperature for holes in CdTe (Triboulet et al., Ref. [74]).

function of temperature. The lower curve is the empirical curve that Yamada [78] fitted to his experimental data for as-grown, nominally undoped p-type samples with room-temperature carrier concentrations of about $5 \times 10^{14} \mathrm{~cm}^{-3}$. The mobility is about $80 \mathrm{~cm}^{2} \mathrm{~V}^{-1} \mathrm{~s}^{-1}$ at $300 \mathrm{~K}$. The curve has the functional dependenee expected for optical mode scattering according to the treatment of Low and Pines [79]. The points shown represent the data of Triboulet et al. [74] for semiinsulating p-type samples with room-temperature carrier concentrations of about $10^{10} \mathrm{~cm}^{-3}$ that were 
grown by the traveling heater method from ingots purified by vertical zone melting. The data are in excellent agreement with Yamada's results. The upper curve represents the theoretical calculations of Kranzer [53]. According to these calculations polar optical mode scattering is the dominant scattering mechanism at room temperature, while this mechanism and acoustic deformation potential scattering are equally important at about $100 \mathrm{~K}$. Piezoelectric and optical deformation potential scattering do not significantly affect the mobility over the temperature range shown.

The time-of-flight technique has been used by the Modena group to measure the drift velocities of electrons and holes in semi-insulating CdTe. The smoothed data of Canali et al. [80] for electrons are shown in figure 30 , where the drift velocity in samples with

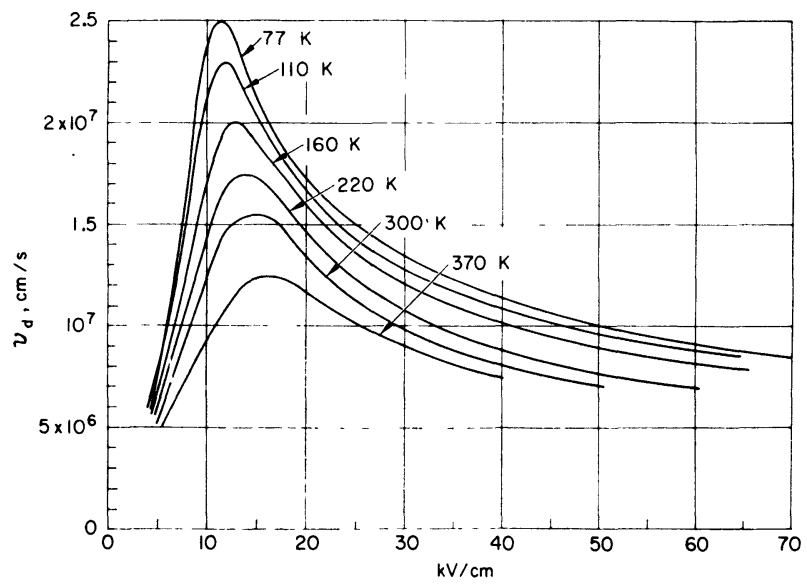

Fig. 30. - Drift velocity vs electric field for electrons in semiinsulating CdTe (Canali et al., Ref. [80]).

resistivities of $10^{8}$ to $10^{9} \Omega . \mathrm{cm}$ is plotted vs electric field for temperatures between 77 and $370 \mathrm{~K}$. With increasing field the velocity initially increases, reaches a maximum, and then decreases due to the transfer of electrons from the conduction band minimum at $\Gamma$ to higher minima. At fields below the velocity maximum the drift mobility at room temperature is in good agreement with the Hall mobility due to lattice scatter- ing that is measured for low-resistivity samples.

Figure 31 shows the data of Ottaviani et al. [81] for the drift mobility of holes in semi-insulating samples as

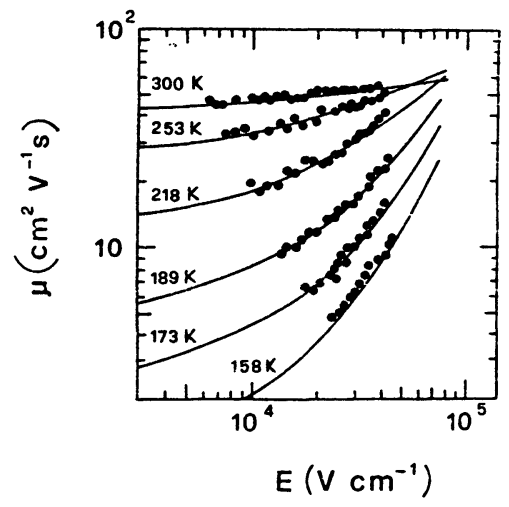

FIG. 31. - Drift mobility vs electric field for holes in semiinsulating CdTe (Ottaviani et al., Ref. [81]).

a function of temperature and electric field. At room temperature the mobility is in fair agreement with the Hall mobility of holes measured on low-resistivity samples, and it does not depend strongly on applied field. With decreasing temperature the drift mobility at fixed field decreases as trapping becomes more important, and it therefore becomes more dependent on field, because the effect of trapping is reduced by the PooleFrenkel mechanism. The curves shown were calculated from the theory for this mechanism by assuming a trap concentration of $5 \times 10^{16} \mathrm{~cm}^{-3}$ and a trap activation energy of $140 \mathrm{meV}$.

The performance of $\gamma$-ray detectors depends critically on the products of mobility and trapping time for electrons and holes. I shall conclude this paper with figure 32, which shows the curves given by Siffert et al. [76] for the $\mu \tau$ products over the years from 1966 through 1974. Alekseenko et al. [54] have reported values for both electrons and holes $-2.6 \times 10^{-3}$ and $4 \times 10^{-4} \mathrm{~cm}^{2} \mathrm{~V}^{-1}$ - that are significantly higher than the best shown. It will be of interest to learn whether this advance is matched or exceeded by the results to be reported at this Symposium.

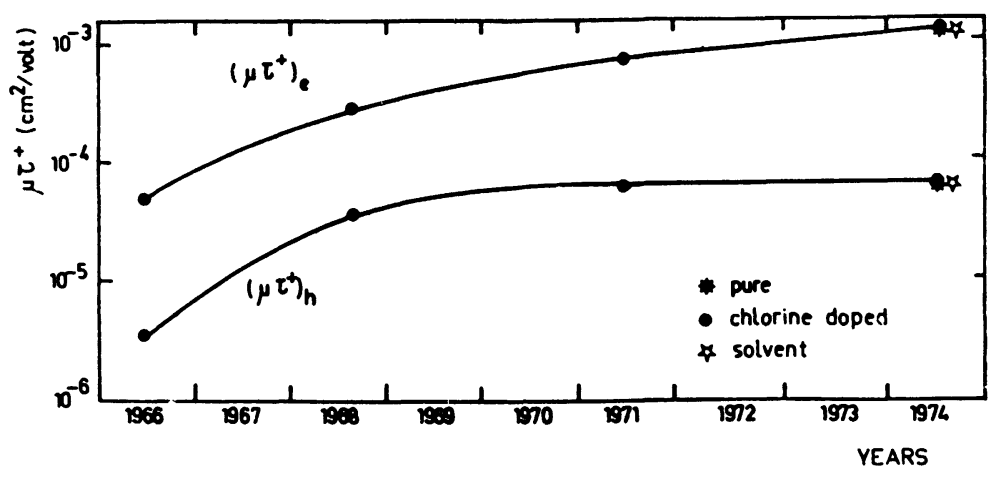

FIG. 32. - Mobility-lifetime products for electrons and holes in CdTe reported from 1966 through 1974 (Siffert et al., Ref. [76]). 


\section{References}

[1] PhIllips, J. C., Bonds and Bands in Semiconductors (Academic Press, New York) 1973, p. 42.

[2] Hirsum, C. and Rose-InNes, A. C., Semiconducting III-V Compounds (Pergamon Press, New York) 1961, frontispiece.

[3] Inoue, M., Teramoto, I. and Takayanagi, S., J. Appl. Phys. 33 (1962) 2578.

[4] Shalimova, K. V., Bulatov, O. S., Voronkov, E. N. and Dimitriev, V. A., Krist. 11 (1966) 480 [Sov. Phys.-Cryst. 11 (1966) 431].

[5] Sînnulescu-Carnaru, I., Phys. Stat. Sol. 15 (1966) 761.

[6] Cline, C. F. and Stephens, D. R., J. Appl. Phys. 36 (1965) 2869.

[7] Yu, W. C. and Gielisse, P. J., Mater. Res. Bull. 6 (1971) 621.

[8] Mariano, A. N. and Warekois, E. P., Science 142 (1963) 672.

[9] Samara, G. A. and Drickamer, H. G., J. Phys. Chem. Solids 23 (1962) 457.

[10] Medvedev, S. A., Maksimovskit, S. N., Kiseleva, K. V., Klevkov, Yu. V. and Sentyurina, N. N., Izv. $A N$ SSSR, Neorg. Mater. 9 (1973) 356 [Inorg. Mater. 9 (1973) 321].

[11] Vaipolin, A. A. and RUd', Yu. V., Izv, AN SSSR, Neorg. Mater. 10 (1974) 550 [Inorg. Mater. 10 (1974) 470]

[12] Vohl, P. and Wolfe, C. M., Electronic Materials Conference, Salt Lake City, Utah, June, 1976, paper F 6.

[13] Vaipolin, A. A., Fiz. Tverd. Tela 15 (1973) 1223 [Sov. Phys. Solid State 15 (1973) 823].

[14] Williams, M. G., Tomlinson, R. D. and HampshiRe, M. J., Solid State Commun. 7 (1969) 1831.

[15] Smith, T. F. and White, G. K., J. Phys. C 8 (1975) 2031.

[16] Greenough, R. D. and Palmer, S. B., J. Phys. D 6 (1973) 587.

[17] Slack, G. A., Phys. Rev. B 6 (1972) 3791.

[17A] Sood, K. C., Singh, M. P. and Verma, G. S., Phys. Rev. B 3 (1971) 385.

[17B] Holland, M. G., Phys. Rev. 134 (1964) 471

[18] Rusakov, A. P., Vekilov, Yu. Kh. and Kadyshevich, A. E., Fiz. Tver. Tela 12 (1970) 3238 [Sov. Phys.-Solid State 12 (1971) 2618]

[19] McSkimin, H. J. and Thomas, D. G., J. Appl. Phys. 33 (1962) 56.

[20] Vekilov, Yu. Kh. and Rusakov, A. P., Fiz. Tver. Tela 13 (1971) 1157 [Sov. Phys.-Solid State 13 (1971) 956].

[21] Berlincourt, D., JAfFe, H. and Shiozawa, L. R., Phys. Rev 129 (1963) 1009.

[22] Swaminathan, V., Selim, F. A. and Kröger, F. A., Phys. Stat. Sol. (a) 30 (1975) 721.

[23] Carlsson, L. and Ahlquist, C. N., J. Appl. Phys. 43 (1972) 2529.

[24] Walford, L. K. and Schoeffel, J. A., Phil. Mag. 21 (1970) 375.

[25] ZubiK, K. and Valvoda, V., Czech. J. Phys. B 25(1975) 1149.

[26] Birch, J. A., J. Phys. C 8 (1975) 2043.

[27] Rowe, J. M., Nicklow, R. M., Price, D. L. and Zanio, K., Phys. Rev. B 10 (1974) 671.

[28] Plumelle, P. and Vandevyver, M., Phys. Stat. Sol. (b) 73 (1976) 271

[29] Perkowitz, S. and Thorland, R. H., Phys. Rev. B 9 (1974) 545.

[30] Serreze, H. B., Entine, G., Bell, R. O. and Wald, F. V., IEEE Trans. Nucl. Sci. NS-21 (1974) 404.

[31] Siffert, P., Gonidec, J. P., Cornet, A., Bell, R. O. and WALD, F. V., Nucl. Instrum. Meth. 115 (1974) 13.

[32] Alberigi Quaranta, A., Canali, C., Ottaviani, G. and Z.ANIO, K. R., Nuovo Cimento Lett. 4 (1970) 908.

[33] Cornet, A., Siffert, P., Coche, A. and Triboulet, R., Appl. Phys. Lett. 17 (1970) 432.
[34] Chadi, D. J., Walter, J. P., Cohen, M. L., Petroff, Y. and Balkanski, M., Phys. Rev. B 5 (1972) 3058.

[35] Freeouf, J. L., Phys. Rev. B 7 (1973) 3810.

[36] Marple, D. T. F., Phys. Rev. 150 (1966) 728.

[37] Thomas, D. G., J. Appl. Phys. 32 (Supp.) (1961) 2298.

[38] See Segall, B., Phys. Rev. 150 (1966) 734.

[39] Camassel, J., Auvergne, D., Mathieu, H., Triboulet, R. and Marfaing, Y., Solid State Commun. 13 (1973) 63.

[40] Loferski, J. J., J. Appl. Phys. 27 (1956) 777.

[41] Babonas, G. A., Bendoryus, R. A. and Shileika, A. Yu., Fiz. Tekh. Poluprov. 5 (1971) 449. [Sov. Phys.-Semicond. 5 (1971) 392.

[42] Melz, P. J. and Ortenburger, I. B., Phys. Rev. B 3 (1971) 3257.

[43] Strauss, A. J. and Iseler, G. W., Bull. Am. Phys. 17 (1972) 326.

[44] Jensen, B., J. Phys. Chem. Solids 34 (1973) 2235.

[45] Vul, B. M., Sal'man, V. M. and Chapnin, V. A., Fiz. Tekh. Poluprov. 4(1970) 67 [Sov. Phys.-Semicond. 4 (1970) 52]

[46] Capek, V., Zimmerman, K., KonaK, C., Popova, M. and Polivka, P., Phys. Stat. Sol. (b) 56 (1973) 729.

[47] Deutsch, T. F., J. Phys. Chem. Solids 34 (1973) 2091.

[48] Magee, T. J., Peng, J. and Bean, J., Phys. Stat. Sol. (a) 27 (1975) 557.

[49] Stafsudd, O. M., HaAK, F. A. and Radisavljević, K., $J$. Opt. Soc. Amer. 57 (1967) 1475.

[50] Danielewicz, E. J. and Coleman, P. D., Appl. Opt. 13 (1974) 1164

[51] Manabe, A., Mitsuishi, A. and Yoshinaga, H., Japan J. Appl. Phys. 6 (1967) 593.

[52] Mears, A. L. and Stradling, R. A., Solid State Commun. 7 (1969) 1267.

[53] Kranzer, D., J. Phys. C 6 (1973) 2977.

[54] Alekseenko, M. V., Arkad'eva, E. N., Kisilenko, V. S., Maslova, L. V., Matveev, O. A., Prokof'ev, S. V. Ryvkin, S. M. and Khusainov, A. Kh., Fiz. Tekh. Poluprov. 8 (1974) 550 [Sov. Phys.-Semicond. 8 (1974) 351].

[55] Strauss, A. J., Proc. Int. Sym. on Cadmium Telluride, Strasbourg, 1971 (P. Siffert and A. Cornet, Eds.), paper I.

[56] Gu, J., Kitahara, T., Kawakami, K. and Sakaguchi, T., J. Appl. Phys. 46 (1975) 1184.

[57] Höschl, P. and Kubálková, S., Czech. J. Phys. B 22 (1972) 530.

[58] Popova, M. and Polivka, P., Czech. J. Phys. B 23 (1973) 110.

[59] Akutagawa, W., Turnbull, D., Chu, W. K. and MaYer, J. W., J. Phys. Chem. Solids 36 (1975) 521

[60] Woodbury, H. H. and Aven, M., Phys. Rev. B 9 (1974) 5195.

[61] Agrinskaya, N. V., Arkad'eva, E. N. and Matveev, O. A., Fiz. Tekh. Poluprov. 5 (1971) 863 [Sov. Phys.-Semicond. 5 (1971) 762].

[62] Segall, B., Lorenz, M. R. and Halsted, R. E., Phys. Rev. 129 (1963) 2471.

[63] Cohn, D. R., LaRsen, D. M. and LaX, B., Solid State Commun. 8 (1970) 1707.

[64] Iseler, G. W., Kafalas, J. A., Strauss, A. J., MacMilLAN, H. F. and BUBE, R. H., Solid State Commun. 10 (1972) 619.

[65] Triboulet, R. and Marfaing, Y., J. Electrochem.Soc. 120 (1973) 1260.

[66] Kun, Z. K. and Robinson, R. B., Electron. Mater. 5 (1976) 23.

[67] Park, Y. S., Hemenger, P. M. and Chung, C. H., Appl. Phys. Lett. 18 (1971) 45 ;

Park, Y. S. and Chung, C. H., Appl. Phys. Lett.18(1971) 99.

[68] Selim, F. A., Swaminathan, V. and Kröger, F. A., Phys. Stat. Sol. (a) 29 (1975) 465. 
[69] Sмiтh, F. T. J., Met. Trans. 1 (1970) 617.

[70] De Nobel, D., Philips Res. Repts 14 (1959) 361.

[71] Gentile, A. L., Kiefer, J. E., Kyle, N. R. and Winston, H. V., Mater. Res. Bull. 8 (1973) 523.

[72] Höschl, P., Polivka, P., Prosser, V. and Sakalas, A., Czech. J. Phys. B 25 (1975) 585.

[73] Wald, F. V. and BeLl, R. O., Nature Phys. Sci. 237 (1972) 13.

[74] Triboulet, R., Marfaing, Y., Cornet, A. and Siffert, P., J. Appl. Phys. 45 (1974) 2759.
[75] Thомpson, A. G., J. Electron. Mater. 2 (1973) 47.

[76] Siffert, P., Cornet, A., Stuck, R., Triboulet, R. and MARFAING, Y., IEEE Trans. Nucl. Sci. NS-22 (1975) 211.

[77] Rode, D. L., Phys. Rev. B 2 (1970) 4036.

[78] Yamada, S., J. Phys. Soc. Japan 15 (1960) 1940.

[79] Low, F. and Pines, D., Phys. Rev. 98 (1955) 414.

[80] Canali, C., Martini, M., Ottaviani, G. and Zanio, K. R., Phys. Rev. B 4 (1971) 422.

[81] Ottaviani, G., Canali, C. and Alberigi Quaranta, A., IEEE Trans. Nucl. Sci. NS-22 (1975) 192. 